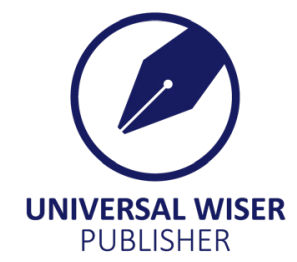

\title{
A Review on Mechanical and Corrosion Behaviour of DMLS Materials
}

\author{
A.P.S.V.R.Subrahmanyam ${ }^{1 *}$, K.Siva Prasad ${ }^{2}$, P.Srinivasa Rao ${ }^{3}$ \\ ${ }^{1}$ Centurion University of Technology \& Management, India \\ ${ }^{2}$ Anil Neerukonda institute of Technology and Sciences, India \\ ${ }^{3}$ Centurion University of Technology \& Management, India \\ Email: subbuaynavilly@gmail.com
}

\begin{abstract}
Direct Metal Laser Sintering (DMLS) is an Additive Manufacturing (AM) technique in which the metal powder will be sintered in selected regions as per 3D CAD file in stack manner in order to produce a three dimensional object with less effort, in less possible time and with minimal wastage of metal. In this paper most widely used DMLS metal powders mechanical and corrosion properties were analyzed and the effect of post processes on the material properties were discussed. The objective of the paper is to fuse the works done so far and to identify gaps to identify the key areas of this technology. The promising and successful application of this revolutionary technology in various sectors like biomedical, aerospace and automotive was also discussed based on material behaviour at different operating conditions. This review would help researchers to find challenges in this booming technology. As per the materials point of view future research prospective was suggested in depth in light of present review.
\end{abstract}

Keywords: DMLS, additive manufacturing, metal powders, mechanical properties, corrosion properties

\section{Introduction}

At present, additive manufacturing (AM) is an invigorated technology in sectors like bio medical, dentistry, aerospace, automobile and manufacturing ${ }^{[1]}$. In this technique, there is an addition of material in a stacking manner to build a prototype or a functional part despite of subtracting material from stock as in the case of conventional machining. Beside of having limited availability of feasible materials and machines, it is emerging technology capable of producing small and medium lot size parts in relatively less time with more accuracy. There is availability of more work space and flexibility of manufacturing due to no tooling. According to ASTM F42, the AM technologies are of two types namely Material Extrusion, Material Jetting, Powder Bed Fusion (PBF), Binder Jetting, Sheet Lamination, VAT Photo Polymerisation and Direct Energy Deposition (DED).

In the present paper we emphasized only on Direct Metal Laser Sintering (DMLS), one of the techniques of PBF. In DMLS metal powders are used to build a 3D object directly from a 3D CAD file. Basically, the final object can be obtained in the machine on a moveable platform by applying powder material as successive layers ${ }^{[2]}$. After a layer was spread by recoater blade, a high power laser beam is directed on to powder bed and it will sinter the powder particles at desired locations as per given 3D file. The platform moves down the pre programmed layer thickness, a fresh film of powder is spread and the next layer is melted with exposure to the laser source, so that it conforms to the previous layer. This process continues, layer by layer, until the object is fabricated. This process was depicted in Figure 1. 


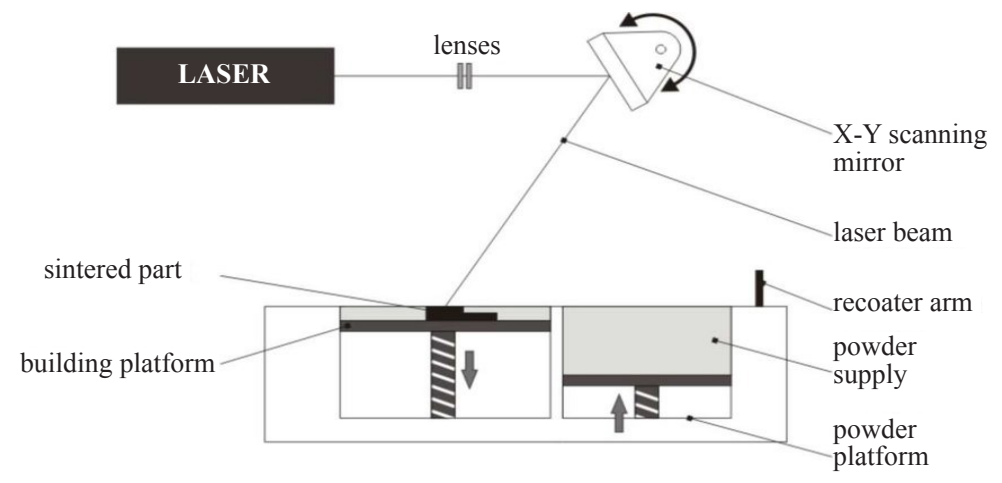

Figure 1. Schematic representation of DMLS process ${ }^{|3|}$

Selective laser melting (SLM) machines are also called as DMLS machines ${ }^{[4,5]}$. In this paper SLM also referred as DMLS. Various European countries produce machines with beds that are able to do laser sintering and laser melting ${ }^{[38]}$. It is a design driven wide spread process because of the availability of different metal powders with desired size, shape and weldability. In this technology it is desirable to have metal powders in the form of spherical and nearly spherical geometry and in tens of micron size to achieve good bonding, homogeneity and crack free products ${ }^{[6]}$. Among the 50 different atomized powders within reach, most widely used metal powders in AM technology are Ti-based alloys, Nickel based super alloys, Al based alloys, Co-Cr alloys, Stainless steels(316Land17-4PH), Precious metals (Au, Ag), Refractory metals(W, Ta), Cu based alloys, intermetallic and low alloy steels ${ }^{[7]}$. In DMLS process a porous internal structure can be used to lessen the weight and assuring the strength at the same time. This results in considerable redeeming in powder material and weight as well as energy consumption during processing ${ }^{[8]}$. This feature of DMLS will attract the automobile sector where there is a continuous research to reduce weight, improve strength and functionality ${ }^{[9]}$.

The main intent of this paper is to analyze studies that were conducted earlier on DMLS Ti-6Al-4V, AlSi10Mg, Stainless Steels, Nickel based super alloys and Co-Cr alloys. The mechanical, tribological and corrosion properties of each of these materials was discussed in detail in the sections 2 . The identified gaps and future concerns were given in conclusions part.

\section{Literature review}

In this section the effect of process parameters and post processes on the performance of DMLS materials reported earlier was discussed ornately.

\subsection{Characteristics of Ti-6Al-4V}

The Ti-6Al-4V alloy is widely used in DMLS process because of its copious applications in biomedical, aerospace, marine and offshore applications. They have good fracture toughness, fatigue behaviour, corrosion resistance and biostability ${ }^{[10,11]}$. DMLS technology helped automakers to produce parts of high quality, cost effective, robust and consistent parts ${ }^{[12]}$, which could be a best alternate to traditional manufacturing processes. Since porous structured parts with desirable strength can be produced. Materials produced by DMLS comprehend few defects that have an effect on their mechanical properties. Various research works conducted to find the effect of input parameters on the defect engenderment in DMLS process. The DMLS product quality depends upon factors like laser power, laser scan speed, hatch distance, laser energy density and layer thickness.

The as built DMLS specimens are prone to cracks due to porosity defects. Porosity defect can form due to meagre energy input or due to the use of extravagant energy ${ }^{[13]}$. So even if the crack initiated was observed to have incessantly started on the surface, the pores network can act as a barrier for the crack proliferation and cause the sample breakdown. Figure 2 shows the defect observed at fractured surface which is irregular in shape and these types of defects are occurred particularly due to fusion paucity and variable particle sizes of powder ${ }^{[14]}$. The possible sources for defect generation are unmelted or partially melted powders particles causing inadequate fusion, delamination between successive passes or earlier deposited layers and inducement of gases during manufacturing. 


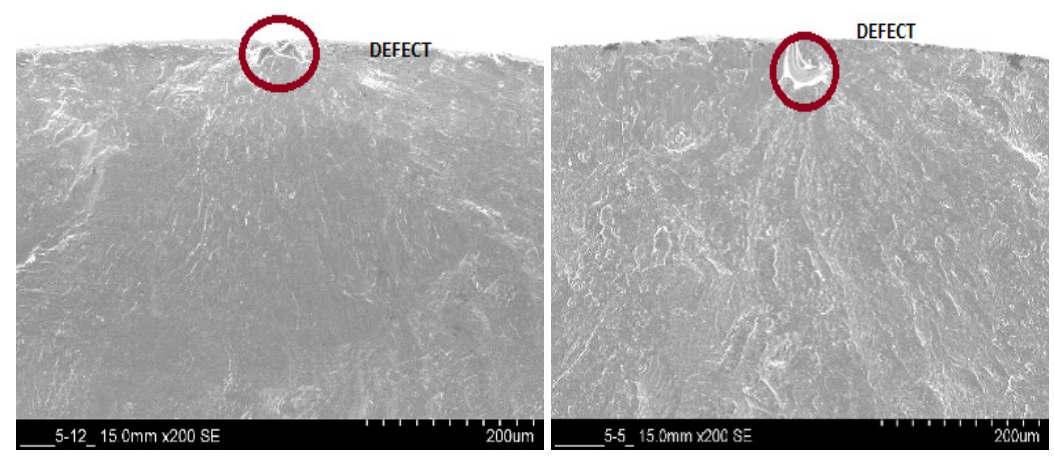

Figure 2. Fatigue fracture origins of surface polished DMLS specimens ${ }^{[13]}$

Excessive or much low energy input lead to emergence of different defect generation mechanisms ${ }^{[15]}$. The hatch distance and scan speed have an impact on surface hardness and final density ${ }^{[16]}$. Decrease in laser speed and hatch distance lead to increased hardness ${ }^{[17]}$. Brazinova et al. ${ }^{[18]}$ studied the effect of laser power on the hardness of Ti-6Al-4V before and after annealing. It was revealed that the hardness and laser power are directly proportional for both perpendicular and parallel directions of the deposit layers before annealing and it was comparatively more in perpendicularly built specimen. After annealing hardness shown negative impact for all laser powers for both build directions due dissolving of material structure pattern. Figure 3 shows the directions with respect to build platform.

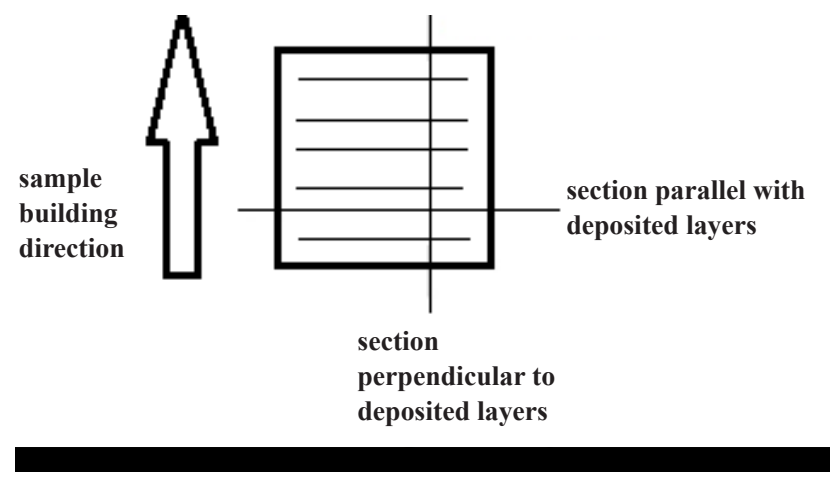

Figure 3. Specimen orientations with respect to build direction ${ }^{[18]}$

Anna Guzanova et al. ${ }^{[19]}$ stated that isotropy in mechanical properties of DMLS component resulted due to stressrelief annealing; it considerably reduced the difference in hardness between the two directions (Parallel and perpendicular to build direction). DMLS products have inherent surface roughness, which will limit their applications in automotive and biomedical applications. The as-built surface roughness can be reduced by some surface machining processes. The inherent surface roughness is mainly due to improper process parameters and partly melted powder particles. The surface roughness has a great effect on fatigue life of DMLS Ti-6Al-4V.The surface roughness depends on powder quality, AM system, Processing parameters and notch orientation. Surface machining improves considerably the fatigue strength of as-built Ti-6Al-4V product produced by DMLS ${ }^{[20]}$. Baca et al. ${ }^{[21]}$ carried out a study on the effect of build orientation on fatigue strength of Ti-6Al-4V made of DMLS and found that the built direction had clear influence on fatigue performance and it was less in specimens built parallel to build direction.

Few authors tried to revamp the fatigue strength of DMLS Ti-6Al-4V by providing some post heat treatment processes. The Hot Isostatic Pressing (HIP) improves ductility of the DMLS Ti-6Al-4V samples due to the formation of $\alpha$ $+\beta$ microstructure and it doesn't have any effect on roughness since there is a limit in size and shape of internal pores ${ }^{[22]}$. The observed microscopic images were shown in Figure 4. Greitemeier et al. ${ }^{[23]}$ suggested that in order to prevent influence of surface roughness on fatigue behaviour of DMLS component HIP was used since, it can minimize the internal defect size. The surface quality of DMLS Ti-6Al-4V can be improved by combining blasting and chemical etching. Blasting minimizes surface irregularities and etching makes surface clean ${ }^{[24]}$. 

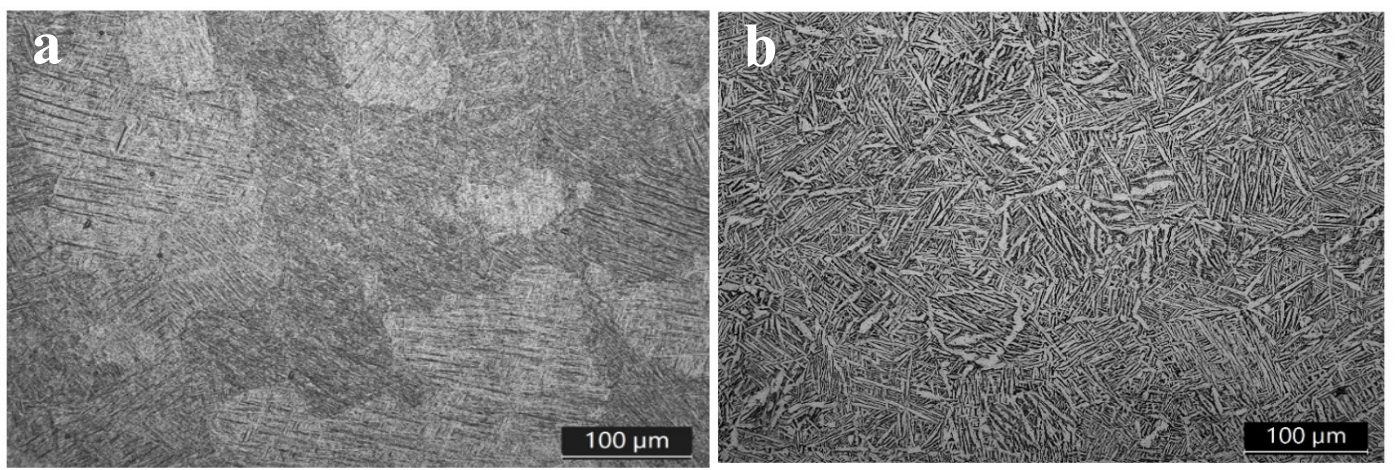

Figure 4. Microstructure of a) As-built b) HIPed DMLS samples ${ }^{[22]}$

Due to rapid cooling in DMLS process there is a change of micro structure from columnar $\beta$ grains to $\alpha$ martensite needle form through which the fatigue crack will grow ${ }^{[25]}$. As-built DMLS Ti-6Al-4V can be used for biomedical applications since after heat treatment at $680^{\circ} \mathrm{C}$ for $3 \mathrm{hrs}$ its tensile strength decreased from $1265 \mathrm{MPa}$ to $1170 \mathrm{MPa}$, while ductility increased by $10.9 \%{ }^{[26]}$. M.G. Moletsane et al. ${ }^{[27]}$ concluded that the properties of DMLS specimens from Ti-6Al$4 \mathrm{~V}$ (ELI) requires only stress-relieving and can meet required standards.

Ti-6Al-4V has excellent biocompatibility, and high corrosion resistance which have resulted in them being used in many engineering and biomedical applications. Ti alloy is widely used in prosthesis, dental restorations and space applications due to its excellent corrosion resistance ${ }^{[28]}$. A corrosive resistant oxide film mainly composed of $\mathrm{TiO} 2$ naturally formed on its surface. The formation of quick and chemically stable protective layer formed on material surface can offer better resistance to corrosion ${ }^{[29]}$. Ti-6Al-4V a duplex structured one, with $\alpha$ phase (hcp) and $\beta$ phase (bcc). Ti-6Al-4V alloy exhibits a wide range of microstructures and is considered to be a heat treatable Ti alloy. When it is heat treated the chemical composition and $\alpha, \beta$ volumes will be altered and show variation in properties. Jhen-Rong et al ${ }^{[30]}$ from their study on corrosion behaviour of Ti-6Al-4V in $0.5 \mathrm{~mol} \mathrm{l}^{-1} \mathrm{H}_{2} \mathrm{SO}_{4}+1 \mathrm{~mol} \mathrm{l}^{-1} \mathrm{HCl}$ solution found that selective dissolution of $\alpha$ phase was occurred when the potential was increased to $-0.9 \mathrm{Vp}_{\mathrm{t}}$ and galvanic corrosion was observed at the boundary of $\alpha$ and $\beta$ phases. From the microstructural analysis of the SLM Ti-6Al-4V, it was clearly evident that it contains high amount of $\alpha$ phase and less amount of $\beta$ phase, whereas grade 5 alloy contain $\alpha+\beta$ phase in its microstructure. This was the reason for inferior corrosion resistance of SLM Ti alloy ${ }^{[31]}$. According to G.A. Longhitano et al ${ }^{[32]}$ the heat treatments combined with anodizing shown more impact in enhancing the corrosion and mechanical properties of Ti-6Al-4V. The anodizing process reduced the passive current density and heat treatment increased $\beta$ phase. There was a difference in corrosion resistance offered by horizontally build and vertically build specimens due to difference in amount of $\alpha$ and $\beta$ phases in cross sectional and longitudinal direction, which shows that anisotropic nature of DMLS material will affect its corrosion resistance ${ }^{[33]}$. R. Żebrowski et al ${ }^{[34]}$ used surface treatment shot peening to improve surface quality of DMLS Ti-6Al-4V and reported that shot peening at low frequencies was found to be effective in reducing surface roughness and improved its corrosion resistance.

Based on the earlier works reported on DMLS Ti-6Al-4V, it is understood that DMLS component contains inherent surface roughness and defects. Proper selection of process parameters plays a major role in the quality of final product. Maximum of works done on mechanical characterization of DMLS product based on process parameters. Post processing is required in order to enhance strength of DMLS product. It is revealed that surface finishing treatments and HIP process improves ductility and fatigue strength. Stress-relief annealing is also required to relief stresses formed during rapid cooling of DMLS product. The works done before on corrosion studies of DMLS Ti-6Al-4V made it clear that it has superior corrosion resistance than cast/ wrought counter parts.

Very few research works identified causes of defects and possible remedies. There is scope remained open to evaluate tribological characterization of DMLS Ti-6Al-4V product. Low cycle fatigue, fatigue crack growth, fracture toughness, impact, creep, creep fatigue, multi axial testing and environmental effects are needed to be explored more. The control of grain growth can possibly be addressed to study anisotropy and change of corrosion resistance between $\alpha$ and $\beta$ phases.

\subsection{Characteristics of AlSi10Mg}

Al-Si base alloys find wide applications due to its high strength to weight ratio, good corrosion and wear resistance. AlSi10Mg alloy can be used for high weight applications due to its high strength, hardness and good resistance to wear. AlSi10Mg is best suited for casting complex and thin walled parts. AlSi10Mg made parts are having the combined 
advantage of good thermal properties and low weight. Al alloy is mostly used in aerospace and automotive interior parts and few functional parts due to its high strength to weight ratio, good thermal conductivity and corrosion resistance ${ }^{[35]}$. Due to near eutectic composition of $\mathrm{Al}$ and $\mathrm{Si}$ they can be easily processed by laser application ${ }^{[36]}$. AlSi10Mg manufactured by DMLS and the effect of process parameters on its properties were studied. The brief review of works reported on DMLS AlSi10Mg was listed here.

Manickavasagam et al. ${ }^{[37]}$ identified that hatching distance and scanning speed showed a much influence on mechanical properties of DMLS AlSi10Mg. The gas entrapment will be increased due to increase in hatch distance which consequently reduces melt pools overlapping. Reducing the scanning speed increases the energy density (LED). Among various process parameters, laser power and hatch distance have more influence on ultimate tensile $\operatorname{strength}^{[38]}$. Wang et al. ${ }^{[39]}$ explored the impact of LED on the surface quality of As-built AlSi10Mg and concluded that the surface quality was improved by increasing LED. The effect of process parameters was studied by Calignano et al. ${ }^{[40]}$ and identified that scan speed has a great influence on surface roughness and shot peening significantly reduced surface roughness as they observed through SEM analysis and were shown in Figure 5. Proper amalgamation of scanning speed and laser power can give better surface finish to DMLS products ${ }^{[41]}$. The powder characterization is also an important factor for DMLS AlSi10Mg. Very fine size powder particles shows negative impact on mechanical properties. Particles less than 10 micron size agglomerate and forms clusters which will avoid flowability and finally causes porosity. Manfredi et al. ${ }^{[42]} \mathrm{used} \mathrm{AlSi} 10 \mathrm{Mg}$ powder particles of spherical shape size ranging from 21 to 27 microns and stated that the ultimate tensile strength, yield strength and elongation at break were improved as compared to cast Al360 alloy.
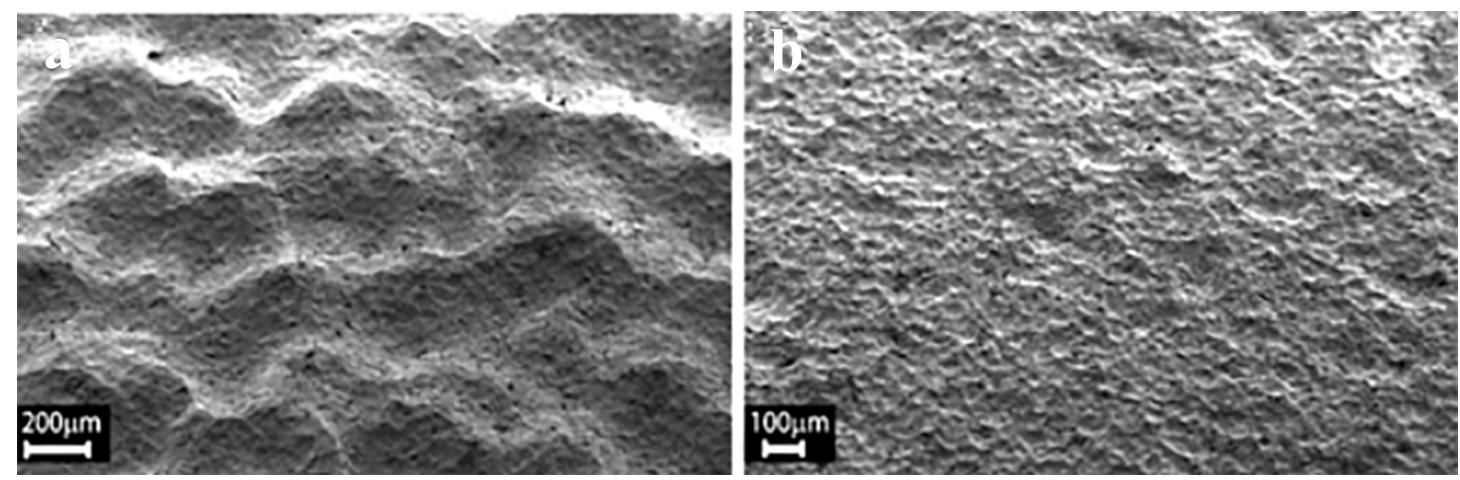

Figure 5. Surface of samples a) before and b) after shot peening ${ }^{[40}$

The parts made by DMLS AlSi10Mg have problem of porosity and surface roughness. The surface quality of DMLS AlSi10Mg had a great influence on its fatigue strength. The As-built DMLS component has inferior fatigue strength when compared to conventional part due to porosity and surface cracks ${ }^{[43]}$. The Al Metal matrix composites reinforced with silicon carbide particulates ( $\mathrm{SiCp}$ ) of different mesh sizes and volume fractions were prepared by Ghosh et al. ${ }^{[44]}$ through DMLS route. They found that with increase in volume percentage of SiCp the Crack density increased and the specific wear rate increased with decrease in mesh size. The small size SiCp increased porosity. The porosity defect was depicted in Figure 6. The reason was coarser grain size lead to gap formation between grains.

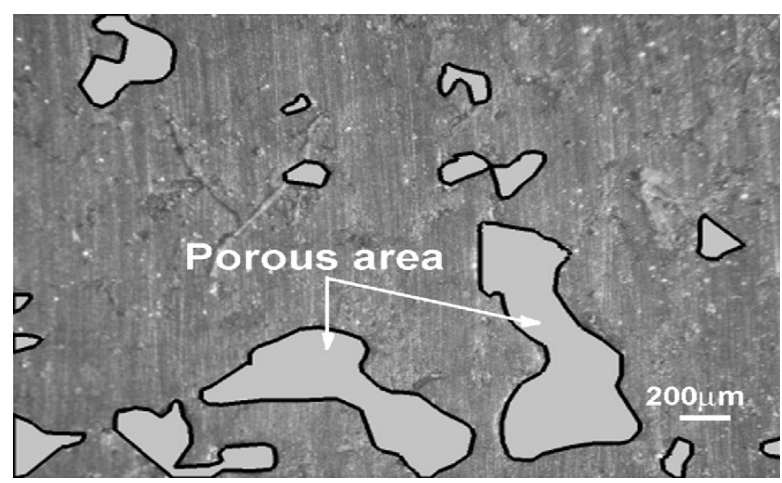

Figure 6. Example photograph showing typical porous area ${ }^{[44]}$ 
Optimized combination of process parameters and surface finish can improve the fatigue strength ${ }^{[45]}$. The fatigue behavior enhancement was always difficult due to defects that remained even after surface polishing. The fatigue crack formation is a major problem in DMLS AlSi10Mg. The sudden cooling of DMLS component from high temperature will create temperature gradient which will induce residual stresses. Heat treatment will make the DMLS component isotropic. Raising the platform temperature will also reduce formation of residual stresses and there by crack propagation ${ }^{[46]}$.

Lorusso et al. ${ }^{[47]}$ studied the tribological behaviour of AlSi10Mg-TiB 2 composite made by DMLS process. They found that DMLS AlSi10Mg-TiB 2 Metal Matrix Composite (MMC) showed less wear than casted AlSi10Mg-TiB 2 Composite. They further suggested that addition of nano sized reinforcements gives better wear properties. The wear rate comparison was shown in Figure 7. Majeed et al. ${ }^{[48]}$ acknowledged that solution heat treatment process reduced the average surface roughness by $17 \%$ at $540^{\circ} \mathrm{C}$ for 2 hours. Sand blasting (post treatment) has a positive effect on DMLS component that reduced average surface roughness by uniform distribution of porosities in the cross section and created superficial compression state in material that improved fatigue resistance ${ }^{[49,50]}$.

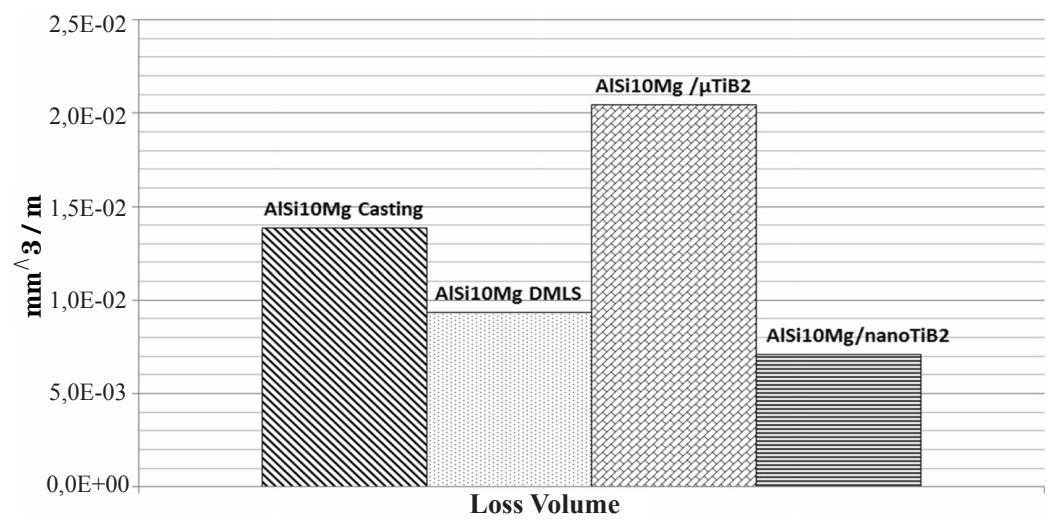

Figure 7. Volume per meter loss after wear tests of the AISi10Mg samples obtained by casting and DMLS, and of the composites with microandnanoTiB particles $^{[47]}$

Due to ever increasing demand in marine and automotive sectors, the additive manufacturing finding its own way of exploring new materials to suit these environments. Among those suitable candidate materials Aluminium alloy (AlSi10Mg) is most preferable one due to its qualities like high strength, light weight and good corrosion resistance. It shows corrosion resistance due to the formation of passive protective film. This passive film acts as a barrier for transfer of ions ${ }^{[51]}$.

Yucheng et al. ${ }^{[52]}$ from their simulation studies concluded that increase in laser power increased corrosion resistance of SLM AlSi10Mg. During laser sintering there was segregation of Si particles and during rapid cooling there was a precipitation. The corrosion characteristics mainly depend on the type of elements present in alloy and the potential difference between them. The potential difference between Al and Si caused galvanic corrosion. The potential difference between $\mathrm{Al}$ and $\mathrm{Si}$ was higher at melt pool boundaries, which would be the most attacked region of corrosion. The cracks formed due to residual thermal stresses during rapid cooling would also promote corrosion. This can be arrested by increasing the build platform temperature. Raising the build platform temperature up to $100^{\circ} \mathrm{C}$ reduces internal stresses without affecting the mechanical and corrosion resistance of DMLS AlSi10 $\mathrm{Mg}^{[53]}$.

The stress reliving post heat treatment at $200-300^{\circ} \mathrm{C}$ caused precipitation of $\mathrm{Si}$ in microstructure and increased selective corrosion attack. The T6 heat treatment and Stress relief heat treatments resulted in Si particles coarsening and lead to microstructural change. The T6 heat treatment destroyed the existed microstructure of as-built SLM Al alloy which further affected its mechanical and corrosion properties ${ }^{[54]}$. The as-built specimen was more sensitive to intergranular corrosion after $24 \mathrm{hrs}$ of immersion time ${ }^{[55]}$. Luca Girelli et al. ${ }^{[56]}$ investigated the corrosion behaviour of DMLS AlSi10Mg and Gravity casted (GC) AlSi10Mg. The as-built DMLS specimen showed superior corrosion resistance than casted counterpart. T6 heat treatment has shown advantage for DMLS alloy in immersion in chloride-bearing environment but it was not effective for casted specimen. The corrosion behaviour of AM Al alloy was better than die casted part in both asbuilt and T6 heat treatment conditions ${ }^{[57]}$. This can be seen from Figure 8. 


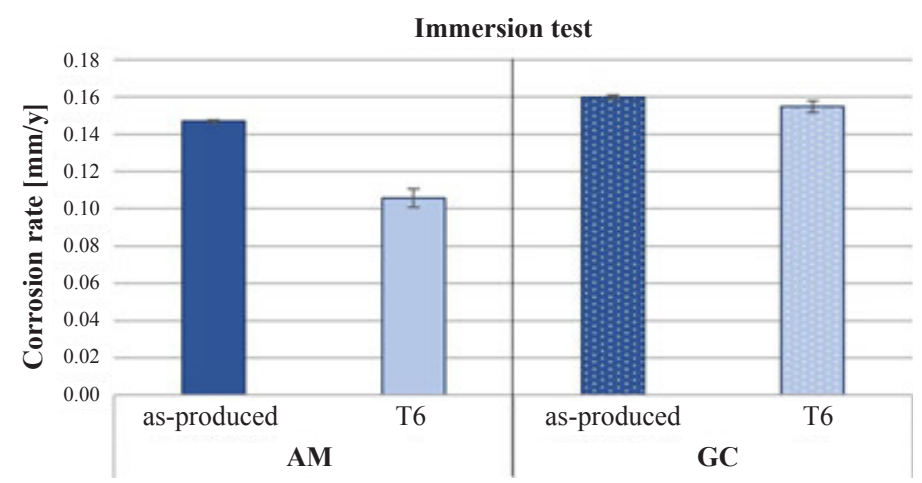

Figure 8. Corrosion rate of DMLS and GC specimens after 28 days of immersion ${ }^{[57]}$

The work done so far on DMLS AlSi10Mg given limited information regarding its mechanical properties. The selection of laser scan speed and power will show a considerable effect on porosity and surface roughness. Some authors came up with possible ways to reduce porosity and surface roughness. Shot peening and solution heat treatment showed a possible impact in decreasing surface roughness and there by fatigue strength. Large number of studies was done on mechanical characterization of DMLS component based on input parameters. It was evident that the corrosion resistance of DMLS AlSi10Mg was better than that obtained by conventional method like casting. This was due to its fine microstructure containing Si particles surrounding eutectic Al particles. Heat treatment at higher temperatures deteriorated the corrosion resistance of DMLS specimen. T6 heat treatment decreased corrosion rate of DMLS specimen. The surface quality plays a vital role in its corrosion resistance. The grounded DMLS specimen has shown better corrosion resistance due to the formation of strong passive film on its surface. The cracks that will initiate due to thermal residual stresses of rapid cooling can be reduced by increasing build platform temperature.

Limited research was addressed on the characterization of DMLS AlSi10Mg product using powder particles size, build orientation and post processing methods. These areas need to be work more. Addition of nano reinforcements in the fabrication of DMLS composites could be a new research area. For better quality of DMLS AlSi10Mg, concern remained open to explore more about process parameters and post or pre treatments to overcome problems listed above.

\subsection{Characteristics of stainless steels}

The stainless steel materials used in DMLS method were SS316Land PH1 steels. Stainless Steel PH1 is a pre-alloyed stainless steel in fine powder form. They have good corrosion resistance and high ductility which makes it a suitable material for biomedical and aerospace. These steels can be moulded into different shapes for different purposes by utilizing the maximum potential of this DMLS technology ${ }^{[58]}$.

Though number of infiltration techniques was suggested for DMLS process, Porosity is still a problem ${ }^{[59]}$. So, proper combination of processes parameters must be used to reduce defects that normally present in DMLS steels. Kurain antony et al. ${ }^{[60]}$ carried out an experiment to understand laser power, scan speed and beam size influence on geometry characteristic and balling effect. They confirmed that laser power and scan speed have noticeable effect on distortion and irregularities. The mechanical properties can be improved by heat treating, changing energy density and combination of input parameters. The post heat treatment also increased the tensile strength in Stainless steel PH1 ${ }^{[6]]}$. This was shown in Figure 9.

Mohamed et al ${ }^{[62]}$ found that horizontal specimens showed better density and mechanical properties than $45^{\circ}$ oriented specimens in the case of 17-4PH Stainless Steel. 


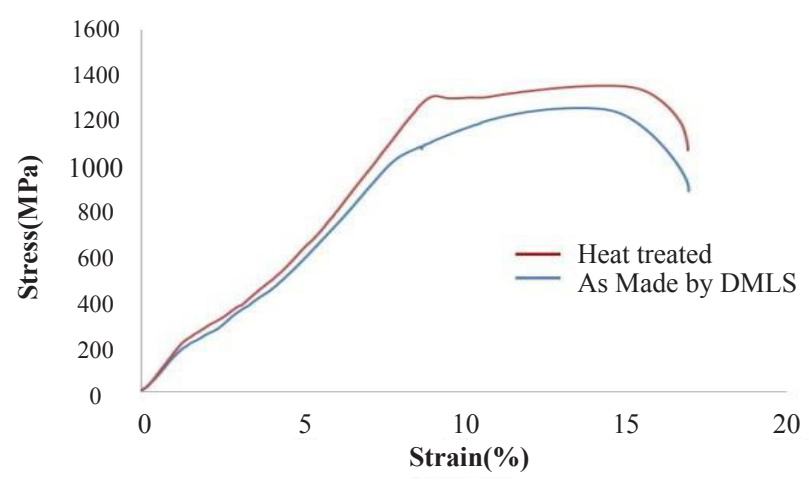

Figure 9. Stress-strain curve of DMLS steel before and after heat treatment ${ }^{[61]}$

Dario et al. ${ }^{[63]}$ studied the effect of built orientation and thickness on the fatigue behaviour of DMLS SS 15-5PH and they concluded that the component built in slant position ( $45^{\circ}$ to build orientation) shown reducing notch effect due to less scan errors. By removing the surface irregularities, residual stresses present at surface can be curtail and may lead to increase of the fatigue strength. Shot peening significantly stored high-magnitude compressive residual stresses on component surface which will improve the fatigue fracture resistance of DMLS component ${ }^{[64]}$. Alafaghani et al. ${ }^{[65]}$ conducted mechanical testing at elevated temperature up to $350^{\circ} \mathrm{C}$ heat treatment and concluded that $15-5 \mathrm{PH}$ can be used in different elevated temperature applications as there was no observable change in their micro structure but there is expected reduction in the tensile mechanical properties. The reduction of mechanical properties with temperature was shown in Figure 10.

Stainless Steel 316L is having high corrosion resistance and it can be used at temperature range below cryogenic temperature. It's kind of austenitic stainless steel commonly used in food processing, medical and aerospace applications. According to Bandyopadhyay et al. ${ }^{[66]}$ the DMLS SS 316L is harder than commercial stainless steel. The laser power is responsible for the quality of product in DMLS. So, the process parameters need to be controlled effectively. It was found that better densification can be achieved with high laser power and low scan rate and less layer thickness and line spacing. In addition to these process parameters the powder properties also showed significant effect on mechanical properties of DMLS Stainless steel.
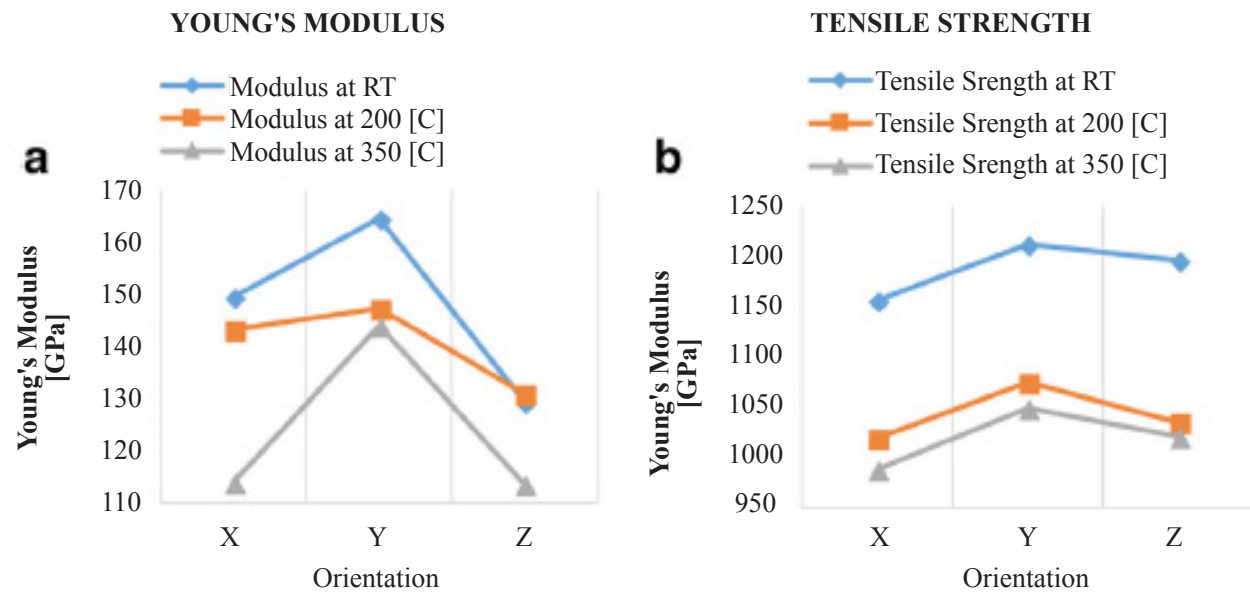

Figure 10. Mechanical properties of $15-5 \mathrm{PH}$ vs orientation at different environmental temperatures ${ }^{[65]}$

Powder chemical composition, particle size and shape show a clear impact on the DMLS product quality. Fine powder particles will increase exposed surface area, which will absorb more laser power, thereby increasing sintering area. Higher laser power will vaporize the metal powder, which is uneconomical. Not only powder properties the laser sintering pattern and laser sintering atmosphere will show a clear influence on densification of product. The delamination problem happens mainly due to thermal gradients present in the material. Figure 11 shows that delamination in different steels at high laser power. The same was reported by Simchi ${ }^{[67]}$. Hussain et al ${ }^{[68]}$ fabricated a MMC through DMLS route using SS316L matrix and CBN reinforcement in nitrogen atmosphere. There was a good compatibility between SS316L and CBN. With increase 
in laser power the relative density of the sintered samples was increased as shown in Figure 12. Increase in CBN content the micro hardness and wear resistance increased but it showed negative impact on relative density as represented in Figure 13.

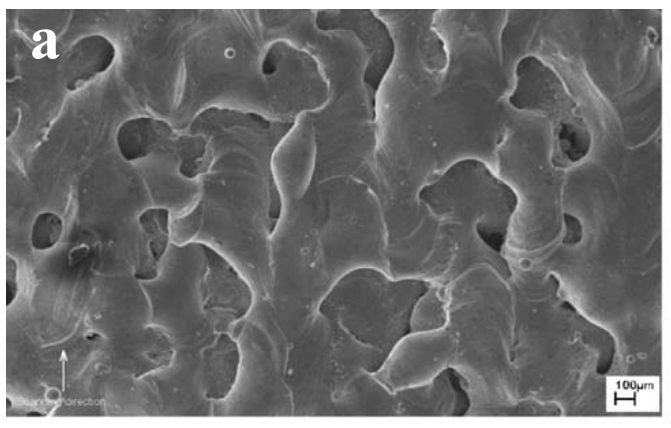

$\mathrm{Fe}-4 \mathrm{Cu}$

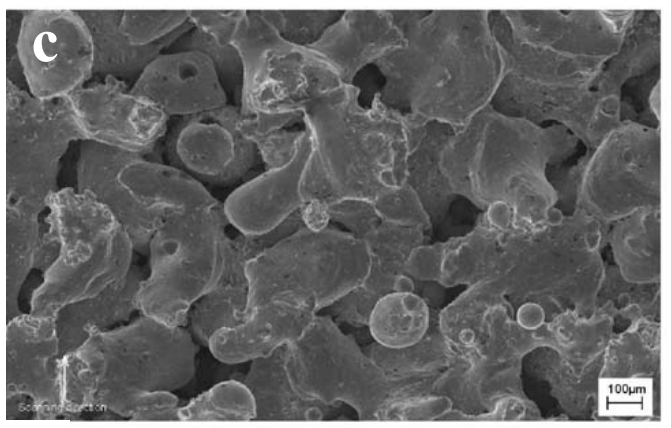

Fe-0.8C

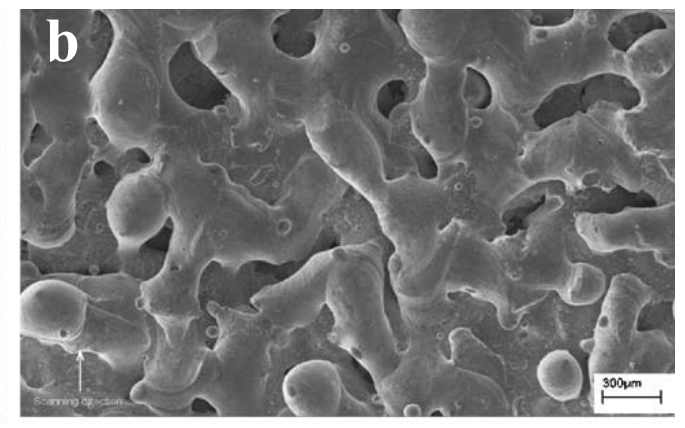

$\mathrm{Fe}-4 \mathrm{Cu}-\mathbf{0 . 3 5 P}$

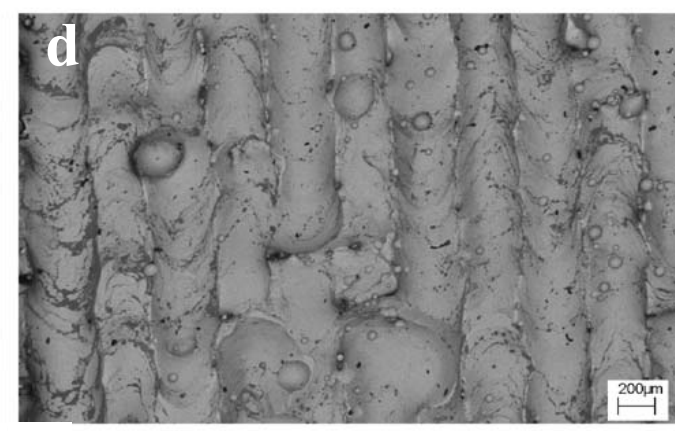

M2 HSS

Figure 11. Example SEM images of different laser sintered steels ${ }^{[67]}$

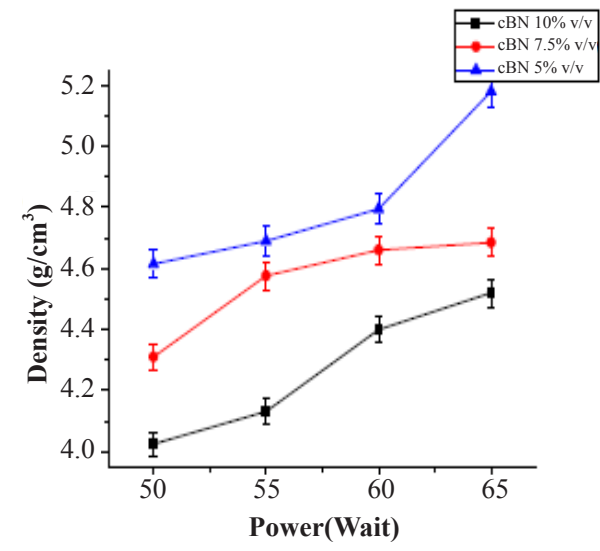

Figure 12. Effect of laser power on density ${ }^{[68]}$

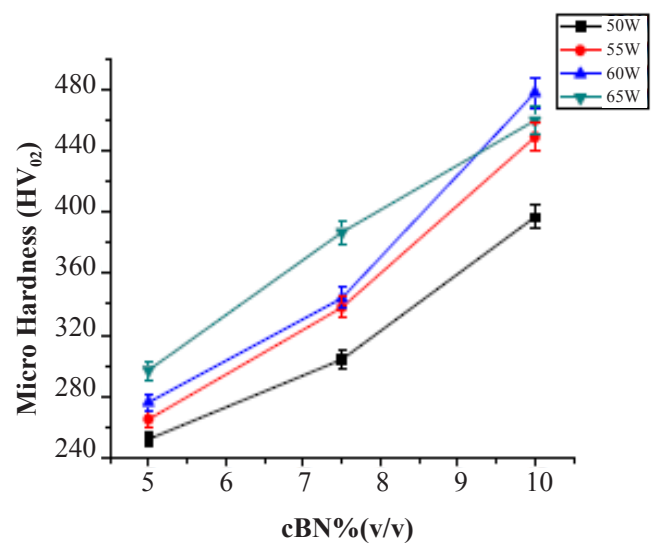

Figure 13. Effect of CBN on the micro hardness ${ }^{|68|}$

Vijay et al ${ }^{[69]}$ fabricated TiN reinforced SS316 metal matrix composite(MMC) and they observed that laser power showed a negative effect on part density and positive effect in reducing porosity up to certain level. With increase in TiN reinforcement the micro hardness of composite was improved. But, further increase in reinforcement after $20 \%$ volume increased wear rate due reduction in bonding between matrix and reinforcement. The previous work on stainless steel concentrated mainly on the influence of process parameters like laser power, scan speed and built orientation on its properties like tensile strength, micro hardness, surface roughness fatigue strength and wear rate. Some works stated that post heat treatment processes improved mechanical properties. There was a good compatibility of reinforcements in steels which improved its wear resistance.

Corrosion of austenitic steels can be classified as general and localized. General corrosion of austenitic stainless steel happens in mineral acids such as hydrochloric, sulphuric and nitric acids. AISI 300 series austenitic steels are corroded by hydrochloric acid solutions. Such attack is due to aqueous $\mathrm{HCl}$ dissociation yielding chloride ions, that attack the passive 
film formed on the steel. Stainless steels belong 300 series subjected to mainly two types of corrosions attacks they are generalized corrosion and localized corrosion. The general corrosion normally happens in mineral acids like hydrochloric, sulphuric and nitric acids, which will deploy the passive film formed on steel surface. The localized corrosion arises due to micro voids on its surface which increases corrosion on those specific regions. The localized corrosion resulted in pitting and intergranular corrosion. Most of previous studies reported that chloride environmental show detrimental effect on corrosion behaviour of steels. The DMLS 316L subjected to pitting corrosion due to voids and porosity that normally produced due to sintering process itself. Chemical segregation at boundaries could also promote this. Heat treatment reduced the microstructural defects and consequently changed the corrosion pattern and morphology of pits formed ${ }^{[70]}$. The pitting corrosion was due to large interfacial stress and micro voids at melt pool boundaries ${ }^{[71]}$. The SLM $316 \mathrm{~L}$ shown more crack growth rate in building direction, which resulted due to pits formed on its surface ${ }^{[72]}$. According to Sander et al.$^{[73]}$ the pitting frequency of SLM $316 \mathrm{~L}$ was lesser than wrought material in chloride solution and passive film formed on SLM specimen is $\sim 1.5$ times thicker than that formed on wrought material. The work done by Gennen et al. ${ }^{[74]}$ confirmed that the HIP process in SLM 316L increased vulnerability of corrosion due to combining of residual cracks and consequently increasing nucleation sites of corrosion. Stainless steel $17-4 \mathrm{PH}$ is precipitation hardening steel containing $3.5 \%$ copper in it. Solution heat treatment followed by aging created soft martensitic microstructure with microscopic $\mathrm{Cu}$ rich phase. Corrosion resistance of precipitation hardening steels mainly depends on chemical composition. The aging heat treatment increased the susceptibility of corrosion cracking ${ }^{[75]}$. The DMLS 17-4 PH subjected to pitting corrosion in chloride environmen ${ }^{[7]}$. The formation of ferrous sulphate salts would play a key role in creation of passive protective film in case of steels. 17-4 PH steel shown better corrosion resistance in $0.5 \mathrm{M} \mathrm{H}_{2} \mathrm{SO}_{4}$ when solution heat treated at $1040^{\circ} \mathrm{C}$ and subsequent aging at temperature $480^{\circ} \mathrm{C}^{[77]}$.

Olugbade et al. ${ }^{[78-81]}$ developed a new method of creating nano structured passive oxide film on surface of steels using surface mechanical attrition treatment (SMAT). They successfully applied this method on the surfaces of SS 316L, 301 and 17-4 PH and found that SMAT was effective in increasing corrosion resistance of these steels. Thanks to Olugbade et al. for their efforts in exploring the possibility of improving the corrosion resistance of stainless steels and further studies need to conduct the adaptability of this SMAT to AM steels.

DMLS steels are showing positive trend after some heat treatments so there is a need to study their effects on micro structure and correlating them with observed properties. Limited work reported on characterization of DMLS steels based on powders size, shape and densification effect. DMLS Steels still need more attention on their corrosion performance and related mechanisms. The microstructural changes have profound effect on their corrosion behaviour. No general conclusions can be drawn according to literature that reported earlier. Limited work required done on the effect of surface treatments on corrosion behaviour of steels. The possibility of mixing different nano reinforcements and their effects on DMLS steels need to be studied.

\subsection{Characteristics of Ni-based super alloys}

The Ni based alloys were developed rigorously in the $20^{\text {th }}$ century, because of their use in jet propulsion, aerospace and more. The Nickel based alloys used in DMLS manufacturing process are Maraging steels, Inconel 625, Inconel 718 and Hastelloy X. These Ni based alloys find wide applications in aerospace and turbo machinery, where there is a need of having low thermal conductivity and good corrosion resistance. Moreover, they are not prone to age hardening and they have high creep life. They not only work well at high temperatures but they can work better even at low temperatures. This is the reason why these Ni based alloys used in cryogenic applications. The turbine engine components can be precisely obtained by DMLS process, because it can produce the quality component with ease ${ }^{[82]}$. Apparao et al ${ }^{[83]}$ fabricated DMLS maraging steel and tested mechanical properties and found that hardness and tensile strength were improved by heat treatment which resulted in precipitated-phase strengthening. Katarina Monkova et al ${ }^{[84]}$ declared that maraging steels mechanical properties were influenced by heat treatment and orientation. The heat treatment effect on conventional and 3D printed steels was shown in Figure 14. 


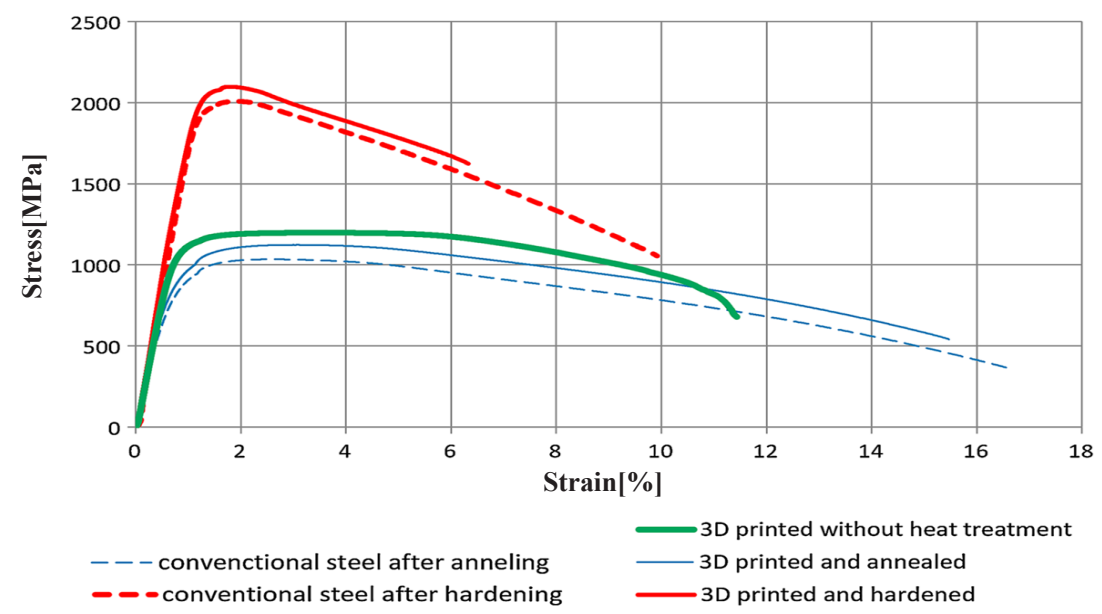

Figure 14. Strain-strain diagram of maraging steel for different heat treatments ${ }^{[84]}$

Jagadish and Priyanka ${ }^{[85]}$ tested the effect of cryogenic treatment and build orientation on DMLS Maraging steel grade 300 mechanical properties. They confirmed that precipitation hardening improved mechanical properties. The cryogenic and aging processes improved the tensile and hardness properties. There was no significant difference in properties of horizontally built specimens and vertically built specimen. The diagrammatic representation was given in Figure 15.

Hadadzadeh et al. ${ }^{[86]}$ used new class of maraging steel known as corrax steel in DMLS process and it contains fine microstructure with an average particle size of $5.2 \pm 1.5 \mu \mathrm{m}$. These grains were equiaxed and decorated with austenite. So, it can be expected to be best choice for high strength applications. Eva Schmidova et al. ${ }^{[87]}$ found that DMLS maraging steel contains fine micro structure when compared to forging or casting and which is responsible for high dynamic and static strength. It was found that aging heat-treatment reduced Plastic anisotropy levels to a greater extent, however, transverse strain anisotropy was likely to remain due to the AM alloy's fabrication history ${ }^{[88]}$.

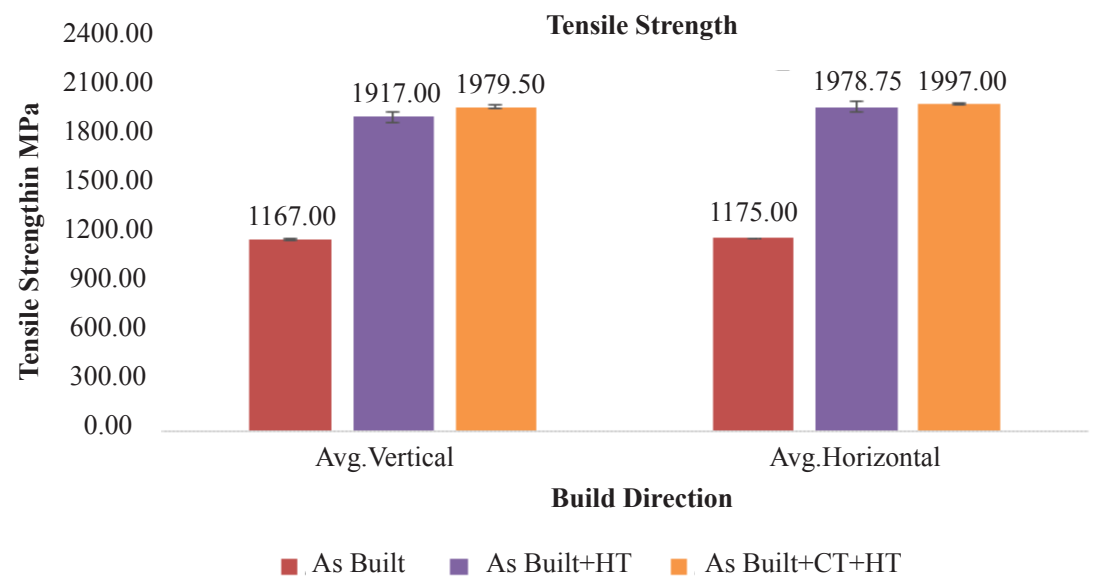

Figure 15. Effect of thermal treatments on Tensile strength ${ }^{[85]}$

The mechanical properties were found to be relying on process parameters and build orientation. The AM parts have some structural and surface defects, which will affect their wear and fatigue behavior. So, there is a need to carry out some post treatments/processes to overcome these defects. Kuo et al. ${ }^{[89]}$ studied the creep properties of DMLS Ni-base superalloy with respect to build direction and heat treatment and concluded that the vertical (perpendicular to build direction) specimens showed higher values of creep life and ductility than horizontal built specimens, because of the interdendritic $\delta$-phase precipitates. The materials creep life and ductility was found to be effected by a row of interdendritic $\delta$-phase with incoherent interfaces. The Dendrite growth is as shown in Figure 16. 


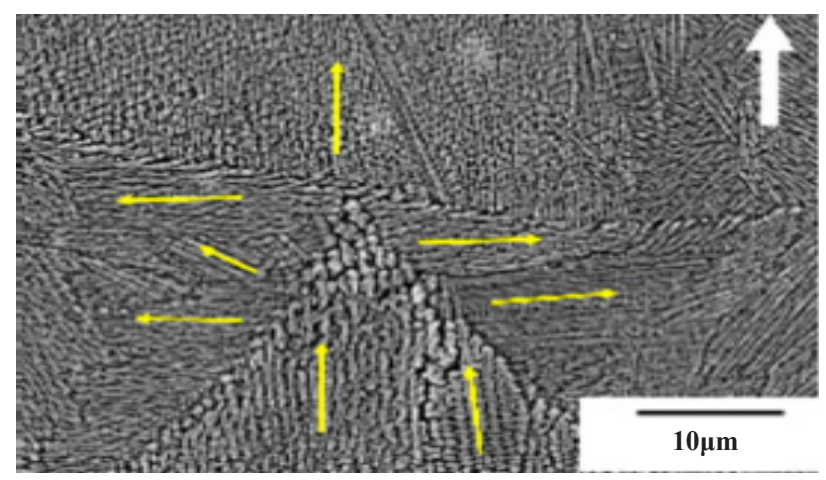

Figure 16. Molten pool boundary with dendrite growth ${ }^{[89]}$

Kelley et al. ${ }^{[90]}$ studied the effect of parameters and build orientation on the properties of DMLS Inconel 718 . There was an improvement of surface finish by post processing (micro machining). The fatigue strength in build orientation in $\mathrm{Z}$ is approximately $14 \%$ lesser than $\mathrm{X} / \mathrm{Y}$ axes. The tensile and yield strengths were found to be $10 \%$ less in $\mathrm{Z}$ direction than X direction. Onome Scott et al. ${ }^{[91]}$ concluded that Nickel alloy 718 was sensitive to DMLS process parameters and post processes like heat treatment and hot isostatic pressing. Components with fine grains were much harder than coarse grains. They found that vertically built specimens showed high tensile strength than horizontal built specimens. They used Ritz method to predict elastic modulus of DMLS Nickel alloy 718 plate and they suggested some alternative methods that might give good measurement of elastic modulus. The DMLS components made of Nickel based powders found wide range of applications in automobile and aerospace sector. So there is a necessity of concentration over its wear and surface roughness. Due to unavoidable surface roughness, the wear rate in DMLS components was relatively higher, the post treatments and optimized input parameters can improve the performance of these additive manufactured parts.

Naiju et al. ${ }^{[92]}$ did research work on wear behaviour of Automobile self-starter center bush and front bush made up of bronze-nickel powder and they found that the wear rate of DMLS component is relatively higher than conventional manufactured bush, but they fall within the acceptable limits. From this, one can improve process performance by developing appropriate processing strategies in order to reduce defects normally arise in AM process. According to Solakolu et al ${ }^{[93]}$ the surface texture of DMLS component can be improved by reducing scanning speed and hatch distance. Surface quality is the main drawback that limits the acceptance of DMLS parts since it can show adverse effect on its properties. Various post processes and heat treatments were tried to improve the surface quality as well as mechanical properties of DMLS Ni alloy based components. Tan, $\mathrm{Yeo}^{[94]}$ were studied surface quality of DMLS Inconel 625 after ultrasonic cavitation abrasive finishing (UCAF). They concluded that UCAF process improved surface quality of as built Inconel 625 significantly and it is shown in Figure 17. This process had removed surface irregularities efficiently without much altering of the DMLS part surface.

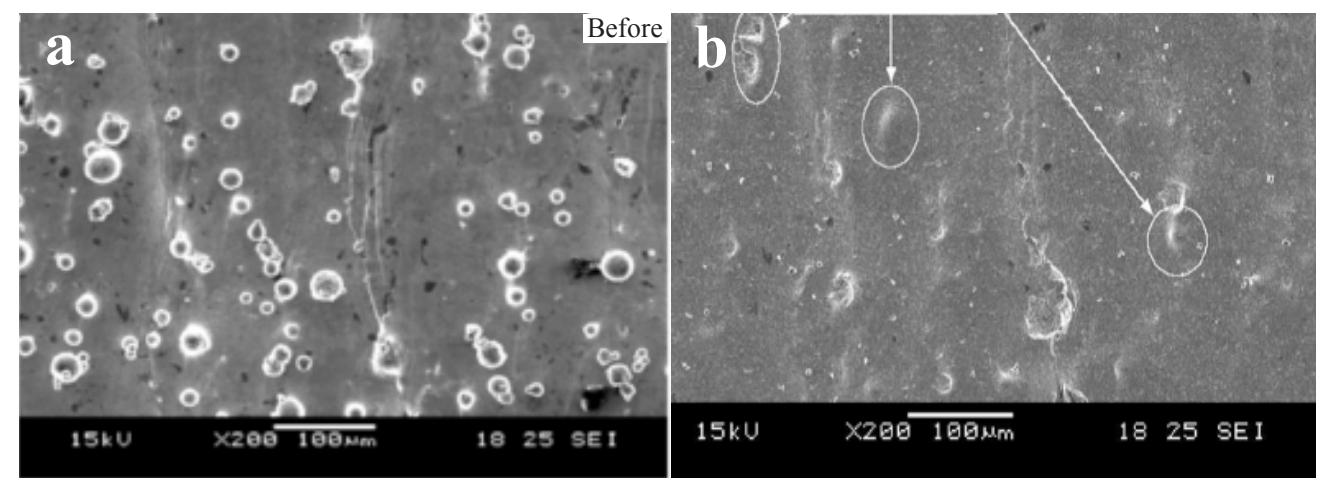

Figure 17. Surface topography of specimen a) before and b) after $\mathrm{UCAF}^{[94]}$

The ascendancy of different process parameters like scan speed, laser scan rate, laser power and hatch distance on micro hardness, final part density, dimensional accuracy and roughness was studied. With increase in laser speed there was increase in micro hardness and decrease in part density of DMLS Inconel 625. They also mentioned that decrease in hatch spacing $(0.3 \mathrm{~mm}$ and $0.4 \mathrm{~mm})$ will decrease micro hardness because of the formation of coarse grains due to low cooling 
$\operatorname{rate}^{[95]}$.

Seetharaman and Krishnan ${ }^{[96]}$ reviewed additive manufactured (DMLS process) Ni based alloys and concluded that the properties of DMLS Ni alloy was greatly influenced by input process parameters and post processes. Powder characterization, thermal conductivity and chemical composition were also important factors while manufacturing through DMLS route. The properties of additive manufactured parts showed better or equal mechanical properties compared to conventional manufactured parts. The influence of powder properties on product quality is shown in Figure 18. There is a need to use DMLS route to manufacture Inconel 718 than conventional manufacturing processes to save material being it is costlier. DMLS process also offers quick and easy method. Ni based alloys can be used in situations where the there is a need of high thermal resistivity and corrosion resistance.

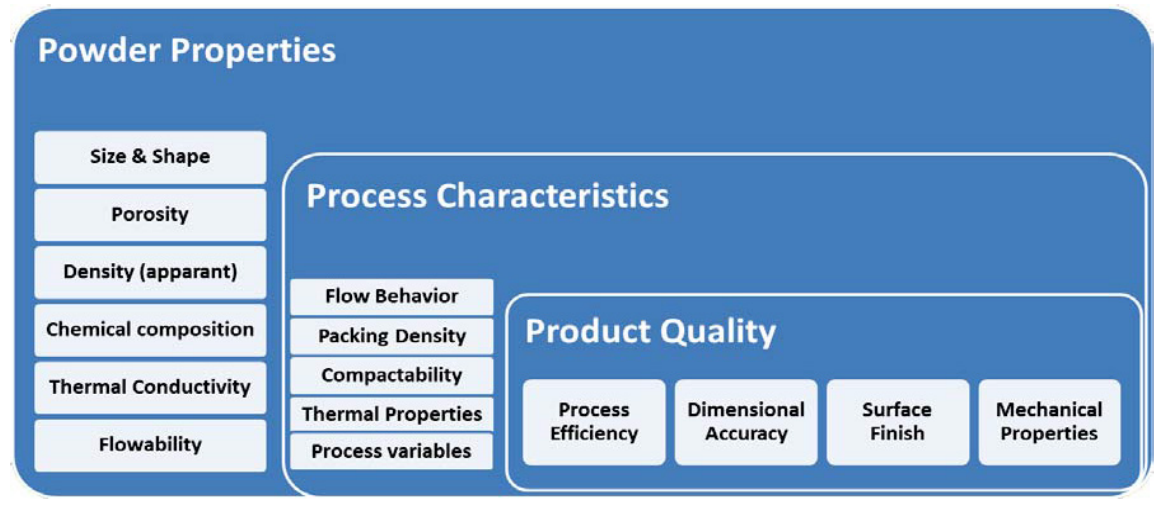

Figure 18. Part quality and process characteristics based on powder properties ${ }^{[96]}$

O.Scott et al. ${ }^{[97]}$ tested the possibility of using DMLS Ni alloy 718 to manufacture hot section components like turbine blade and heat exchangers and compared tensile and fatigue properties of DMLS component with cold rolled Ni. Tensile properties were observed to be comparatively high for DMLS Ni alloy 718 mainly in transverse build direction. For high temperature and corrosion resistance applications like gas turbine blades, air craft engines and for process in which usage of chemicals there is a need of such alloy known as Hastelloy X. It is a Ni-Cr-Fe-Mo alloy. Wrought Hastelloy X exhibits a high tensile strength of $800 \mathrm{MPa}$ and a percent elongation of approximately $50 \%$ at room temperature ${ }^{[98]}$. Hastelloy X can be used for the flame tube and casing of the combustion chamber due to its high creep strength and corrosion and oxidation resistance ${ }^{[99]}$. The alloy has nickel-based austenitic structure, called gamma $(\gamma)$ that can be strengthened by the addition of alloying elements ${ }^{[100]}$. While the addition of molybdenum and iron increases the strength, Hastelloy X is primarily used for its high corrosion resistance, because of its chromium content ${ }^{[101]}$. Chromium improves the oxidation resistance because it forms a protective $\mathrm{Cr}_{2} \mathrm{O}_{3}$ oxide layer on the surface. This oxide layer is specifically known for its hot corrosion resistance.

There is a problem in using Hastelloy $\mathrm{x}$ through DMLS route because of the formation of micro cracks resulted from porosity and residual stresses. So there is a compromise in its mechanical properties. The methods like Solid solution strengthening, addition of carbides, heat treatments, hot isostatic pressing were improved its mechanical properties. Abbaschian et al. ${ }^{[102]}$ altered the composition of Hastelloy X by adding Molybdenum to increase its solid solution strength thereby decreasing the crack density and marked an improvement of mechanical properties.

Ni super alloys can be used in severe operating conditions due to its excellent corrosion resistance, high temperature resistance and ability to withstand at high stresses. These Ni super alloys form a thin oxide layer on its surface which separates its surface from aqueous solution but tribological contact will deteriorate this thin film and will cause pitting attack and stress corrosion cracking ${ }^{[103]}$. The Ni super alloys find wide application in oil and gas industry where there is a need of material that can resist sulphide stress corrosion cracking (SSCC). Inconel 625 has high resistance to pitting and high Ni content make this more protected to chloride stress corrosion. Selective corrosion behaviour of SLM Inconel 625 was studied by et al. ${ }^{[104]}$ and they found that there was less penetration of acid attack for SLM 625 compared to hotworked, heat treated wrought alloy (Grade 1625 ). The mass loss was also less for SLM product. They further reported that heat treatment at $980^{\circ} \mathrm{C}$ followed by quenching prevented depth of penetration of selective attack. Inconel 718 used widely to make turbine blades due to its ability to withstand at high temperature and high corrosion resistance. It contains high amount of Niobium which forms a passive oxide film against corrosion. Heat treatment caused the DMLS Inconel 718 to isotropy nature with more uniform austenitic microstructure and electrochemical corrosion was less than commercial alloy. They concluded that heat treatment improved corrosion resistance against aggressive corrosion environment ${ }^{[105]}$. 
From past reported studies it is clear that Ni alloys plays a vital role in aerospace and aviation sector, where there is a need to have good thermal resistivity, corrosion resistance, better mechanical, fatigue and wear properties. Majority of researchers reported the effect of input parameters on mechanical as well as on surface quality of DMLS products. Some of the findings of earlier researchers revealed that post processing improved surface quality, fatigue and creep life. The effect of build orientation was also studied by few researchers and they found that specimens build in transverse direction (vertical specimens) showed better properties. Limited work published on corrosion resistance of DMLS Nickel alloys. They have high resistance to pitting and selective crack corrosion (SCC) but they have less resistance to intergranular corrosion. Heat treatment at suitable temperatures can increase Ni super alloys corrosion resistance.

There is need to study the impact of different orientations on fatigue as well as mechanical properties. More focus needed to be done on Powder characterization and its effect on properties like part density and surface defects. More literature was present on Inconel 625 and Inconel 718 and maraging steel. Very few works reported on Hastelloy X. Being Ni alloys are relatively costlier and significant engineering materials; DMLS is best AM technique which considerably saves time and material despite of its ability to develop complex parts.

\subsection{Characteristics of $\mathrm{Co}-\mathrm{Cr}$ based alloys}

In order to produce bio medical parts form Co-based alloys, AM techniques were used in the recent past. Co alloys are high tensile strength and biocompatible material mostly used for medical and turbine engine applications. Cast cobaltbase alloys were originally proposed for surgical implants over 60 years ago. Metallurgical uses of cobalt exploit its properties such as high temperature strength, biocompatibility, high wear and corrosion resistance, magnetic properties, low expansion coefficient etc. It is widely used in gas turbine nozzles, jet engine blades and vanes and hard facing wear resistant applications ${ }^{[106]}$.

Compared to casting AM is more suitable for fabrication of dental prosthesis. In casting material expands and contracts during formation of wax patterns and there is a problem of defects like blowholes which will affect the strength of product. But in this laser sintering process dimensional accuracy is more and dense parts without blow holes can be easily obtained in relatively less time. Additive manufacturing (AM) can be more productive if the resources used efficiently ${ }^{[107]}$, providing high density and homogeneity in work piece ${ }^{[108,109]}$.

Co-Cr alloy was used in manufacturing of artificial implants such as hips, knees and bone plates. There are no allergic problems by using Co-Cr alloys, since they are nickel free alloys ${ }^{[110]}$. These can be used for high load bearing applications due to their high strength and toughness. DMLS could be better choice to make surgical implants from Co-Cr-Mo alloys due to manifestation of increased hardness and uniform microstructure ${ }^{[111]}$.Cobalt-based alloys finds wide application in other areas like nuclear power plants, rocket fuel nozzles and turbine engine vanes where there is high temperature, oxidation, and hot corrosion ${ }^{[112]}$. In the field of dental restorations, DMLS is more productive, economic and time saver because it offers good repeatability and faster delivery in the production of metal-ceramic fixed partial dentures (FPDs) ${ }^{[113]}$.

Koutsoukis et al. ${ }^{[114]}$ concluded that DMLS is more time and cost effective process to manufacture dental restorations where it is possible to achieve more or similar properties that we generally obtain by casting or milling. The SEM images of Laser sintered, milling and casted Co-Cr samples were shown in Figure 19.

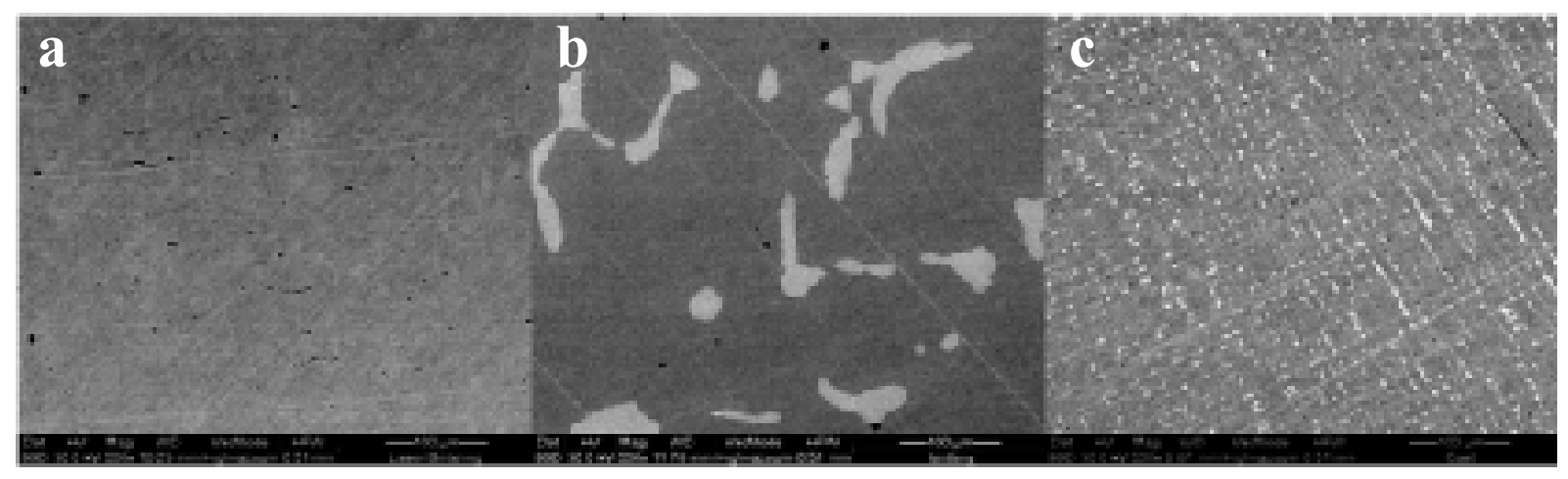

Figure 19. SEM images from the polished cross-section of Co-Cr dental alloys fabricated by a) SLM

b) Milling and c) Casting ${ }^{[14]}$

Puskar et al. ${ }^{[115]}$ used artificial saliva to do comparative corrosion study of DMLS and Cast (CM) Co-Cr-Mo Dental Alloy. They concluded that highest elution observed in high acidic environment and ion release is more in Co. Less elution 
observed for DMLS alloy in all acidic environments than cast metal. The density variations are shown in Table 1.

Table 1. Density of DMLS and Cast (CM) Samples ${ }^{[115]}$

\begin{tabular}{cccccc}
\hline \multirow{2}{*}{ Sample } & \multicolumn{5}{c}{ Density $\rho\left(\mathrm{g} / \mathrm{cm}^{3}\right)$} \\
& $\rho_{\text {average }}$ & $\rho_{\text {median }}$ & $\rho_{\text {stdev }}$ & $\rho_{\text {min. }}$ & $\rho_{\text {max. }}$ \\
\hline CM & 8.22 & 8.22 & 0.02 & 8.02 & 8.24 \\
DMLS & 8.60 & 8.59 & 0.03 & 8.52 & 8.66 \\
\hline
\end{tabular}

Diana-Irinel et al ${ }^{[116]}$ studied the effect of hydroxyapatite (HA) $\mathrm{Ca}_{5} \mathrm{HO}_{13} \mathrm{P}_{3}$ coating on DMLS Co-Cr samples, they found that the hydroxyl apatite formed after immersion in simulated biological fluid (SBF) is uniform (Shown in Figure 20) and the implants have a better adherence to the bone. The faster healing of the patient was observed. Diana-Irinel ${ }^{[117]}$ used Co-Cr alloy for dental restorations and stated that DMLS was a best process to make dental restorations because part being produced was having limited mechanical stress due to good sinter and mechanical properties of Co-Cr powder. The products made by laser sintering were shown in Figure 21.

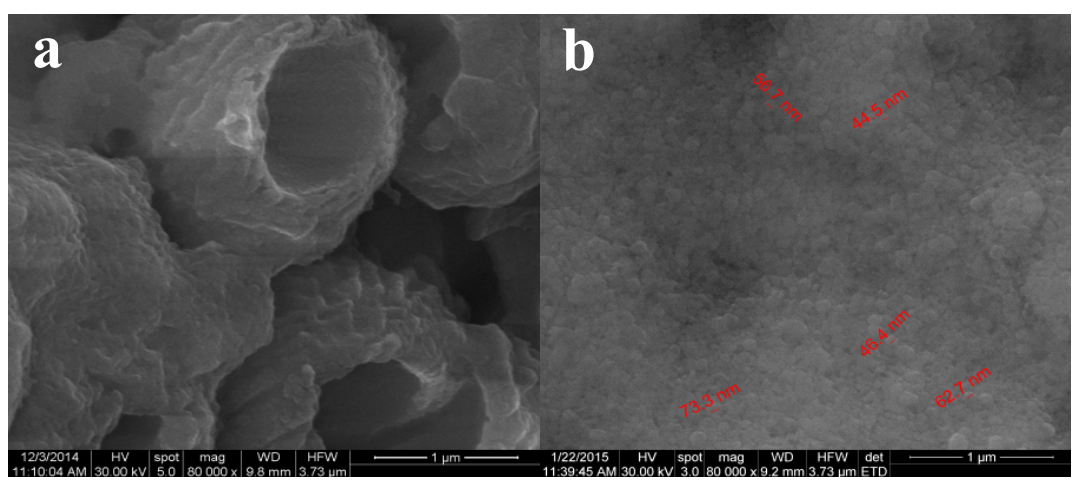

Figure 20. FE-SEM images of sintered sample treated and coated with 2 layers with HA, (a) Before and (b) After immersion in $\mathrm{SBF}^{[116]}$
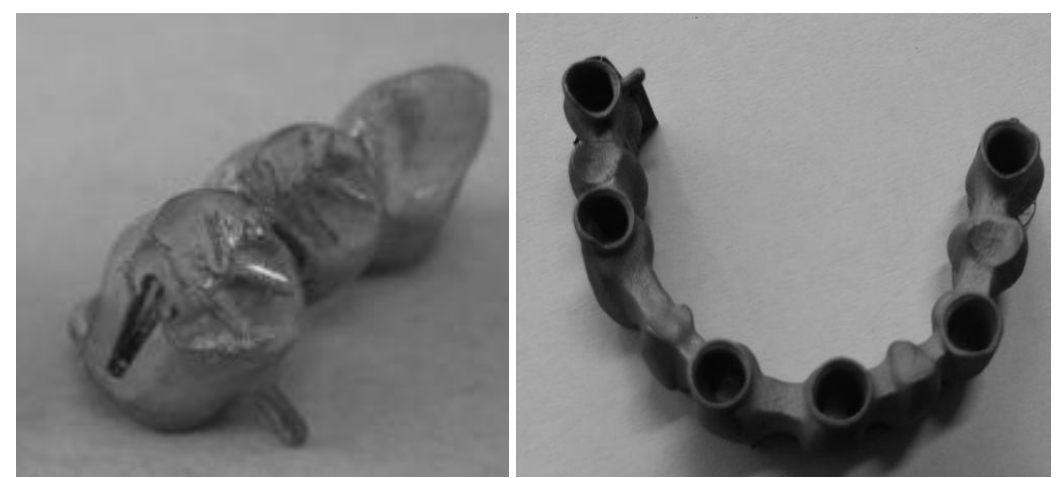

Figure 21. Examples of DMLS Dental Bridge and Dental Crown of Co-Cr metal ${ }^{[117]}$

DMLS Co-Cr-Mo alloy can be used in dental applications because of its excellent mechanical properties like high ultimate tensile strength, the elongation at break and the hardness ${ }^{[118]}$. The durability of DMLS made dental clasps was superior to that of cast clasps. Additive manufacturing was best technology than dental casting ${ }^{[119]}$. Josef et al. ${ }^{[120]}$ claimed that DMLS made Co-Cr-Mo dental clasps contain relatively less porosity compared to casted specimens. They can sustain for long time due to higher consistency of retentive forces. The quality of clasps mainly depends on input laser power, speed and layer thickness which will decide porosity levels and micro structure in the laser sintered part ${ }^{[121]}$ did not affect the mechanical properties of the layered manufactured alloy was not influenced by powder characteristics and the layer thickness ${ }^{[122]}$. Since DMLS involves utilization of high laser power more heat is generated during manufacturing and rapid cooling also takes place, due to this some thermal stresses will remain in the products, which will lead to thermal strain which is not desirable. So, better strength can be obtained with some post heat treatments ${ }^{[123]}$.

Swee et al. ${ }^{[124]}$ fabricated laser sintered Co-Cr-Mo samples and were solution heat treated. After heat treatment the both ultimate tensile strength (UTS) and yield strength (YS) decreased due to carbides formation, but the as built specimens 
showed twice the values in UTS and YS of casted Co-Cr-MO alloys. Solution heat treatment process showed a great effect on mechanical properties of DMLS Co-28Cr-6Mo alloy, since solution heat treatment increased ductility and reduces yield strength $^{[125]}$. Solution heat treatment lead to the microstructural transformation which improved its mechanical properties significantly ${ }^{[126]}$.

Co-Cr alloys are widely used in the dental restorations due to their high biocompatibility, high strength and good corrosion resistance. The components manufactured by SLM process contain anisotropic nature non-uniform physical and metallurgical properties. The corrosion behaviour needs to be concentrated more carefully because the release of corrosive products during service can cause adverse health problems. The bio-fluids became aggressive due to presence of oxygen, chloride ions and biological macromolecules during inflammatory conditions ${ }^{[127]}$. The wear of metal components leads to the dissolution of passive film, so that the body fluids can cause corrosion to $\mathrm{Co} \mathrm{Cr}$ alloys ${ }^{[128]}$. Takaichi et al ${ }^{[129]}$ the selection process parameters will produce different types of dissolved metal ions which will affect SLM Co29Cr6Mo alloy corrosion resistance. According to Erica Liverani et al. ${ }^{[130]}$ concluded that SLM process parameter which resulted in higher mechanical properties determined worse corrosion behaviour. They also proposed low laser power and high scan speed for surface fabrication while high power, low scan speed suggested for bulk material fabrication. The passive film composition on surface of Co-Cr alloy mainly depends on the chemical composition of solution in contact with its surface ${ }^{[131]}$. So, this can be expected that the alloy will exhibit different corrosion behaviour for different solutions. Electrochemical Impedance Spectroscopy (EIS) indicated that the passive film formed on $\mathrm{Co}-\mathrm{Cr}$ alloy in $0.9 \% \mathrm{NaCl}$ solution showed higher corrosion resistance than that was formed in Phosphate Buffer Solution $(\mathrm{PBF})^{[132]}$. Xian-zhen Xin et al. ${ }^{[133]}$ from their studies confirmed that SLM built samples bear the surface microstructural and anti-corrosion properties that meets with the demands of dental clinics.

The Co-Cr metal is best suitable for biomedical applications mainly in dentistry which resulted in porous surface with desired strength. The porous surface is desirable for better adherence with body tissues. The sintered micro structure resulted in better mechanical properties than conventional methods. So DMLS is the best method for fabrication of artificial prosthesis using $\mathrm{Co}-\mathrm{Cr}$ metals. The corrosion studies indicated that the corrosion resistance of $\mathrm{Cr}$-Co alloy mainly depends on the elements in solution that is in contact with its surface. The process parameters should be controlled properly so that better corrosion resistance can be obtained for SLM products.

The works reported so far on DMLS Co-Cr-Mo mainly focused on the compatibility to use in dentistry. It's a better material for the manufacturing of prosthesis due to its high strength and hardness. Since it is nickel free alloy, it is safe to use in prosthesis preparation. in human body. It is known for its good thermal and corrosion resistance which makes it ideal material for the fabrication of aircraft fuel nozzles and vanes. The load carrying capacity and various methods to improve it should be studied further.

\section{Conclusions}

The following conclusions are drawn based on works reported by various researchers on DMLS process.

The DMLS made parts were showing better mechanical properties than wrought, cast or forged parts due to fine microstructure observed in DMLS made parts is distinct from the microstructures that observed in conventional manufacturing processes.

RegardingTi-6Al-4V, from the review it is clear that, it is a light alloy with excellent mechanical properties, low specific weight with good biocompatibility. So it's a suitable material for aerospace and medical fields. Post processing like HIP is required to improve its fatigue strength.

The corrosion resistance of DMLS Ti-6Al-4V is superior/equal to cast or wrought counter parts. The corrosion in Ti alloy is anisotropic nature due to its duplex nature.

For good strength and thermal characteristics AlSi10Mg is the best suitable material in DMLS process. The studies on DMLS AlSi10Mg reported that there is a need to improve surface quality, in order to enhance the fatigue life. The pre heat treatment of build platform showed a considerable improvement of fatigue life and shot peening diminishes surface roughness.

The corrosion behaviour of AlSi10Mg mainly depends on the microstructure formed after corrosion. The T6 heat treatment homogenized the microstructure and there is no selective corrosion attack. The surface quality plays a vital role in its localized corrosion attack.

DMLS Stainless steel exhibits good mechanical properties with better fatigue strength. The laser power and scan speed clearly have impact on their mechanical properties. Post heat treatments showed improvement in their mechanical properties. 
The solution heat treatment followed by annealing favors the corrosion resistance against stress corrosion cracking of stainless steel 17-4 PH. Proper heat treatment. The duplex steels are highly susceptible to stress corrosion cracking.

Because of their excellent thermal and corrosion resistivity properties DMLS Ni alloys are playing vital role in aviation and aerospace industries. They retain high strength at elevated temperatures due to precipitation hardening.

DMLS Ni super alloys have high pitting and corrosion cracking resistance. The heat treatment at suitable temperature can improve their corrosion resistance.

Due to superior mechanical properties and bio compatibility of DMLS Co-Cr alloys they mainly used in dentistry to make dental restorations. DMLS is appropriate method for fabrication of implants and dental restorations because there is more design freedom and one can obtain patient specific implants.

The process parameters resulted in higher mechanical properties determines worse corrosion resistance and vice versa.

\section{Future scope}

For DMLS Ti-6Al-4V, there is a need to do explore more about its compressive strength, creep resistance and to find suitable post processing methods to improve its fatigue strength by reducing crack propagation tendency. In order to use it as a successful material in biomedical filed proper methods should be adopted to decrease its elastic modulus despite of losing its strength. There is a need to explore more about degradation mechanism mainly in the contribution of proteins and bio organisms.

For DMLS AlSi10Mg, the surface quality is not up to the desired level. So, researchers should try to find better ways to reduce as-built surface roughness, which is adverse effect on its fatigue strength. There is a need to explore about the effect of surface finishing process over its corrosion studies.

For DMLS Steels concern remains open for better control of input parameters and post heat treatments to extend its applications. Few works reported on its tribological behaviour. Efforts required in reducing the inherent defects like porosity and surface quality to improve corrosion resistance. So the area remained open for future study.

For DMLS Ni based alloys there is need to reduce anisotropy and residual stresses which mainly occurs due to directional solidification and rapid cooling. So, proper build orientation and process parameters optimization could be stimulated. The collapse or depletion of Niobium oxide layer is still a problem in chloride and bromide solutions, which needs to be studied further.

For DMLS Co-Cr alloy the ductility is less, so it's a challenging area for the researchers to work on. Very limited works reported on its dilution nature and corrosion behaviour. There is a need to optimize process parameters to improve its mechanical and corrosion behaviour. The means to improve its corrosion resistance at the interface of metal oxide layer and phosphate solution possibly studied.

\section{Conflict of interest}

The authors declare that there is no conflict of interest regarding the publication of this paper.

\section{References}

[1] Frazier, W. E. Metal additive manufacturing, a review. Journal of Materials Engineering and Performance. 2014; 23(6): 1917-1928.

[2] D. A. Hollander, M. Von Walter, T. Wirtzetal. Structural, mechanical and in vitro characterization of individually structured Ti-6Al-4V produced by direct laser forming. Biomaterials. 2006; 27: 955-963.

[3] C. Mangano, M. Raspanti, T. Traini, et al. Stereo imaging and cytocompatibility of a model dental implant surface formed by direct laser fabrication. Journal of Biomedical Materials Research Part A. 2009; 88: 823-831.

[4] Aumund-Kopp C., Petzoldt, F. Laser sintering of parts with complex internal structures. Proceedings of the 2008 world congress on powder metallurgy \& particulate materials, Washington D.C, USA. 2008; 1: 385-397.

[5] Chunze Yan, Liang Hao, Ahmed Hussein, et al. Evaluation of light-weight AlSi10Mg periodic cellular lattice structures fabricated via direct metal laser sintering. Journal of Materials Processing Technology. 2014; 214 : 856-864.

[6] Stephane Gorsse, Christopher Hutchinson, Mohamed Gouné, et al. Additive manufacturing of metals, a brief review of the characteristic microstructures and properties of steels, Ti-6Al-4V and high-entropy alloys. Science and Technology of Advanced Materials. 2017; 18(1): 584-610.

[7] Available materials for metal additive manufacturing, characteristics \& applications. Farinia Group. Available from: 
https://www.farinia.com/additivemanufacturing/3dmaterials/characteristics-and-applications-ofavailable-metals-foradditive-manufacturing.

[8] Liciane Sabadin Bertol, Wilson Kindlein Júnior, Fabio Pinto da Silva, et al. Medical design, direct metal laser sintering of Ti-6Al-4V. Materials and Design. 2010; 31: 3982-3988.

[9] David E. Cooper, Mark Stanford, Kevin A. Kibble, et al. Additive manufacturing for product improvement at red bull technology. Mark, Materials and Design. 2012; 41: 226-230.

[10] Gu D, Meiners W, Wissenbach K, et al. Laser additive manufacturing of metallic components materials, processes and mechanisms. International Materials Reviews. 2012; 57: 133-164.

[11] Sallica-Leva E, Jardini AL, Fogagnolo JB. Microstructure and mechanical behavior of porous Ti-6Al-4V parts obtained by selective laser melting. Journal of Mechanical Behaviour of Biomedical Materials. 2013; 26: 98-108.

[12] Sunil Hebbalakar. Unveiling additive manufacturing with metal powders industry trends with technology interventions and competitive landscape as frame of reference. Metal Powder Report. 2018; 73(4): 198-201.

[13] Gong, Haijun, Rafi, H., et al. Influence of defects on mechanical properties of Ti-6Al-4V components produced by selective laser melting and electron beam melting. Materials and Design. 2015; 86: 545-554.

[14] Hiroshige Masuo, Yuzo Tanak a, Shotaro Morokoshi, et al. Effect of defects, surface roughness, HIP on fatigue strength of Ti6Al4V manufactured by additive manufacturing. Structural Integrity Procedia. 2017; 7: 19-26.

[15] H. Attar, M. Calin, L. C. Zhang, et al. Manufacture by selective laser melting and mechanical behaviour of commercially pure titanium. Materials Science and Engineering A. 2014; 593: 170-177.

[16] Wang, J. H., Cheng, J., Li, Y. X., Bai, et al. Influence of laser scan speed on density and mechanical properties of a Ti6Al4V part produced by means of selective laser melting (SLM). Lasers Engineering. 2012; 23: 395-401.

[17] Liciane Sabadin Bertol, Wilson Kindlein Junior, Fabio Pinto da Silva, et al. Medical design, direct metal laser sintering of Ti-6Al-4V. Materials and Design. 2010; 31: 3982-3988.

[18] Janette Brezinova, Radovan Hudak, Anna Guzanova, et al. Direct metal laser sintering of Ti6Al4V for niomedical applications, microstructure, corrosion properties, and mechanical treatment of implants. Metals. $2016 ; 6: 171$.

[19] Anna Guzanova, Gabriela Izarikova, Janette Brezinová, et al. Influence of build orientation, heat treatment and laser power on the hardness of Ti6A14V manufactured using the DMLS process. Metals. 2017; 7: 318-335.

[20] R. Konecnaa, G. Nicolettob, S. Fintovac, et al. As-built surface layer characterization and fatigue behavior of DMLS Ti6A14V. Structural Integrity Procedia. 2017; 7: 92-100.

[21] Adrian Bacaa, Radomila Konecna, Gianni Nicoletto, et al. Influence of build direction on the fatigue behaviour of Ti6Al4V alloy produced by direct metal laser sintering. Materials Today Proceedings. 2016; 3: 921-924.

[22] M. Benedetti, M. Cazzollia, V. Fontanaria, et al. Fatigue limit of Ti6Al4V alloy produced by selective laser sintering. Procedia Structural Integrity. 2016; 2: 3158-3167.

[23] D. Greitemeier, C. Dalle Donne, F. Syassen, et al. Effect of surface roughness on fatigue performance of additive manufactured Ti-6Al-4V. Materials Science and Technology. 2016; 32(7): 629-634.

[24] Guilherme Arthur Longhitanoa, Maria Aparecida Larosa, André Luiz Jardini Munhoz, et al. Surface finishes for Ti6Al-4V alloy produced by direct metal laser sintering. Materials Research. 2015; 18(4): 838-842.

[25] Radomila Konecna, Ludvik Kunzb, Adrian Baca, et al. Long fatigue crack growth in Ti6Al4V produced by direct metal laser sintering. Procedia Engineering. 2016; 160: 69-76.

[26] Yadroitsev P, Krakhmalev I. Yadroitsava. Selective laser melting of Ti6A14V alloy for biomedical applications, temperature monitoring and micro structural evolution. Journal of Alloys and Compounds. 2014; 583: 404-409.

[27] M. G. Moletsane, P. Krakhmalev, N. Kazantseva, et al. Tensile properties and microstructure of direct metal lasersintered Ti6A14V (ELI) alloy. South African Journal of Industrial Engineering. 2016; 27(3): 110-121.

[28] I. M. Pohrelyuk, V. M. Fedirko, O. V. Tkachuk, et al. Corrosion resistance of Ti-6Al-4V alloy with nitride coatings in ringer's solution. Corrosion Science. 2013; 66: 392-398.

[29] P. Handzlik, K. Fitzner. Corrosion resistance of Ti and Ti-Pd alloy in phosphate buffered salinesolution with and without $\mathrm{H}_{2} \mathrm{O}_{2}$ addition. Trans. Nonferrous Met. Soc. China. 2013; 23: 866-875.

[30] Jhen-Rong Chen, Wen-Ta Tsai. In situ corrosion monitoring of Ti-6Al-4V alloy in $\mathrm{H}_{2} \mathrm{SO}_{4} / \mathrm{HCl}$ mixed solution using electrochemical AFM. Electrochimica Acta. 2011; 56: 1746-1751.

[31] Nianwei Dai, Lai-Chang Zhang, Junxi Zhang, et al. Corrosion behaviour of selective laser melted Ti-6Al-4V alloy in $\mathrm{NaCl}$ solution. Corrosion Science. 2016; 102: C484-489.

[32] G. A. Longhitano, M. A. Arenas, A. Conde, et al. Heat treatments effects on functionalization and corrosion behavior of Ti-6Al-4V ELI alloy made by additive manufacturing. Journal of Alloys and Compounds. 2018; 319. Available from: doi:10.1016/j.jallcom.2018.06.319.

[33] Qingxuan Sui, Peizhen Li, Kunlun Wang, et al. Effect of build orientation on the corrosion behavior and mechanical properties of selective laser melted Ti-6Al-4V. Metals. 2019; 9: 976.

[34] R. Żebrowski, M. Walczak. The effect of shot peening on the corrosion behaviour of ti-6al-4v alloy made by DMLS. 
Advances in Materials Science. 2018; 18(3): 43-54.

[35] E. O. Olakanmi, R. F. Cochrane, K. W. Dalgarno. A review on selective laser sintering/melting (SLS/SLM) of aluminium alloy powders, Processing, microstructure, and properties. Progress in Materials Science. 2015; 74: 401477.

[36] Louvis, E., Fox, P., Sutcliffe, J. Selective laser melting of aluminium components. Journal of Materials Processing Technology. 2011; 211: 275-284.

[37] Manickavasagam krishnan eleonora atzeni riccardo canali flaviana calignano diego manfredi elisa paola ambrosio luca iuliano. On the effect of process parameters on properties of AlSi10Mg parts produced by DMLS. Rapid Prototyping Journal. 2016; 20(6): 449-458.

[38] R K Shah, P P Dey. Process parameter optimization of DMLS process to produce AlSi10Mg components. IOP Conf. Series: Journal of Physics: Conf. Series. 2019; 1240: 012011.

[39] Lin.-zhi Wang, Sen Wang, Jiao-jiao. Wu. Experimental investigation on densification behavior and surface roughness of AlSi10Mg powders produced by selective laser melting. Opt. Laser. Technol. 2017; 96: 88-96.

[40] F. Calignano, D. Manfredi, E. P. Ambrosio, et al. Influence of process parameters on surface roughness of aluminum parts produced by DMLS. Int. J. Adv. Manuf.Technol. 2013; 67: 2743-2751.

[41] Y. Ning, J. Y. H. Fuh, Y. S. Wong, et al. An intelligent parameter selection system for the direct metal laser sintering process. Int. J. Prod. Res. 2004; 42: 183-199.

[42] Diego Manfredi, Flaviana Calignano, Manickavasagam Krishnan, et al. From powders to dense metal parts, characterization of a commercial AlSiMg alloy processed through direct metal laser sintering. Materials. 2013; 6: 856-869.

[43] Todd. M. Mower n, Michael J. Lon. Mechanical behavior of additive manufactured, powder-bed laser-fused materials. Materials Science \& Engineering A. 2016; 651:198-213.

[44] Subrata Kumar Ghosh, Partha Saha, Shyam Kishore. Influence of size and volume fraction of SiC particulates on properties of ex situ reinforced $\mathrm{Al}-4.5 \mathrm{Cu}-3 \mathrm{Mg}$ metal matrix composite prepared by direct metal laser sintering process. Materials Science and Engineering A. 2010; 527: 4694-4701.

[45] Ana D. Brandao, Johannes Gumpinger, Michael Gschweitl, et al. Fatigue properties of additively manufactured AlSi10Mg-surface treatment effect", 3rd international symposium on fatigue design and material defects. Procedia Structural Integrity. 2017; 7: 58-66.

[46] Riccardo Casati, Milad Hamidi Nasab, Mauro Coduri, et al. Effects of platform pre-heating and thermal-treatment strategies on properties of AlSi10Mg alloy processed by selective laser melting. Metals. 2018; 8: 954.

[47] Massimo Lorusso, Alberta Aversa, Diego Manfredi, et al. Tribological behavior of aluminum alloy AlSi10Mg-TiB 2 composites produced by direct metal laser sintering (DMLS). Journal of Materials Engineering and Performance. 2016; 8: 3152-3160.

[48] ArfanMajeed, Altaf Ahmed, Abdus Salam, et al. Surface quality improvement by parameters analysis, optimization and heat treatment of A1Si10Mg parts manufactured by SLM additive manufacturing. International Journal of Lightweight Materials and Manufacture. 2019; 2: 288-295.

[49] Andrea Avanzini, DavideBattini, Marcello Gelfia, et al. Investigation on fatigue strength of sand-blasted DMLSAlSi10Mg alloy. Procedia Structural Integrity. 2019; 18: 119-128.

[50] Annalisa Pola, Davide, Battini, et al. Evaluation on the fatigue behavior of sand-blasted AlSi10Mg obtained by DMLS. Fratturaed Integrità Strutturale. 2019; 49: 775-790.

[51] Yucheng Ji, Chaofang Dong, Decheng Kong, et al. Design materials based on simulation results of silicon induced segregation at AlSi10Mg interface fabricated by selective laser melting. Journal of Materials Science \& Technology. 2020; 46: 145-155.

[52] Marina Cabrini, Flaviana Calignano, Paolo Fino, et al. Corrosion behavior of heat-treated AlSi10Mg manufactured by laser powder bed fusion. Materials. 2018; 11(7): 1051.

[53] Luca Girelli, Marialaura Tocci, Lorenzo Montesano, et al. Investigation of cavitation erosion resistance of AlSi10Mg alloy for additive manufacturing. Wear. 2018; 402: 124-136.

[54] Gokhan Özer, Gürkan Tarakçi, Mustafa S. Yilmaz, et al. Investigation of the effects of different heat treatment parameters on the corrosion and mechanical properties of the AlSi10Mg alloy produced with direct metal laser sintering. Materials and Corrosion. 2019: 1-9.

[55] Tim Rubben, Reynier I. Revilla, Iris De Graeve. Influence of heat treatments on the corrosion mechanism of additive manufactured AlSi10Mg. Corrosion Science. 2018; 152: 101-108.

[56] P. Fathi, M. Rafieazad, M. Mohammadi, et al. Effect of surface finishing procedures on corrosion resistance of DMLSAlSi10Mg_200C alloy. Proceedings of the 16th International Aluminum Alloys Conference (ICAA16). 2018.

[57] P. Fathi, M. Ra fieazada, X. Duana, et al. On microstructure and corrosion behaviour of AlSi10Mg alloy with low surface roughness fabricated by direct metal laser sintering. Corrosion Science. 2019 ; 157: 126-145. 
[58] Das, S., Beama, J., Wohlert, M., et al. Direct laser freeform fabrication of high performance metal components. Rapid Prototyping Journal. 1995; 4: 112-117.

[59] O’neill, W., Sutcliffe, C. J., Morgan, R., et al. Investigation on multi-layer direct metal laser sintering of 316L stainless steel powder beds. CIRP Annals-Manufacturing Technology. 1999; 48(1): 151-154.

[60] Kurian Antony, N. Arivazhagan, K. Senthilkumaran. Numerical and experimental investigations on laser melting ofstainless steel 316L metal powders. J Manuf. Process. 2017; 16: 345-355.

[61] Snehashis Pala, Hanuma Reddy Tiyyaguraa, Igor Drstvenšeka, et al. The effect of post-processing and machining process parameters on properties of stainless steel PH1 product produced by direct metal laser sintering. Procedia Engineering. 2016; 149: 359-365.

[62] Mohamed Shehata, Tarek M. Hatem, Wael A. Samad. Experimental study of build orientation in direct metal laser sintering of 17-4PH stainless steel. 3d Printing and Additive Manufacturing. 2018; 6: 227-233.

[63] Dario Croccolol, Massimiliano De Agostinis, Stefano Fini, et al. Effects of build orientation and thickness of allowance on the fatigue behaviour of 15-5 PH stainless steel manufactured by DMLS, Fatigue. Fract. Eng. Mater. Struct. 2017; 41: 1-17.

[64] Vinoth Jebaraj, A., Sugavaneswaran, M. Influence of shot peening on residual stress distribution and corrosion resistance of additive manufactured stainless steel AISI 316L. Transactions of the Indian Institute of Metals. 2019; 72(6): 1651-1653.

[65] Ala'aldin Alafaghani, Ala Qattawi, Mauricio Alberto Garza Castañón. Effect of manufacturing parameters on the microstructure and mechanical properties of metal laser sintering parts of precipitate hardenable metals. The International Journal of Advanced Manufacturing Technology. 2018; 99: 3491-2507.

[66] P. P. Bandyopadhyay, D. Chicot, C. S. Kumar, et al. Influence of sinking-in and piling-up on the mechanical properties determination by indentation, A case study on rolled and DMLS stainless steel. Materials Science \& Engineering A. 2013; 576: 126-133.

[67] A. Simchi. Direct laser sintering of metal powders, mechanism, kinetics and microstructural features. Materials Science and Engineering A. 2006; 428: 148-158.

[68] M. Hussain, V. Mandal, P. K. Singh, et al. Experimental study of microstructure, mechanical and tribological properties of cBN particulates SS316 alloy based MMCs fabricated by DMLS technique. Journal of Mechanical Science and Technology. 2017; 31(6): 2729-2737.

[69] Vijay Mandal, Manowar Hussain, Vikas Kumar, et al. Development of reinforced TiN-SS316 metal matrix composite(MMC) using direct Metal laser sintering (DMLS) and its characterization. Materials Today, Proceedings. 2017; 4: 9982-9986.

[70] C. Prieto, D. Young, M. Singer, et al. Pitting corrosion resistance of a 316L stainless steel manufactured by the direct metal laser sintering process. Corrosion. 2019; 75(2): 140-143.

[71] Ni, Xiao-qing, Kong Decheng, Wen Ying, et al. Anisotropy in mechanical property and corrosion resistance of 316L stainless steel fabricated by selective laser melting. Int. J. Min. Met. Mater. 2018; 26: 319-328.

[72] Strondl, A., Lyckfeldt, O., Brodin, H., et al. Characterization and control of powder properties for additive manufacturing. JOM. 2015; 67: 549-554.

[73] Sander, Guilherme, Thomas, S., et al. On the corrosion and metastable pitting characteristics of 316L stainless steel produced by selective laser melting. J. Electrochem. Soc. 2017; 164: C250-C257.

[74] K. Geenen, A. Rottger, W. Theisen. Corrosion behaviour of 316 $\mathrm{L}$ austenitic steel processes by selective laser melting, hot-isostatic pressing, and casting. Materials and Corrosion. 2017; 68(7): 764-775.

[75] M. Karaminezhaad, S. Sharafi, K. Dalili. Effect of molybdenum on SCC of 17-4 PH stainless steel under different aging conditions in chloride solutions. J. Mater. Sci. 2006; 41: 3329-3333.

[76] Z. Cheng, C. Kwok, K. Lo. Laser surface melting of 17-4 PH precipitation-hardenable stainless steel. Pacific International Conference on Application of Lasers \& Optics. 2010; 1203.

[77] Aneta Szewczyk-Nykiel, Jan Kazior. Effect of aging temperature on corrosion behavior of sintered 17-4 PH stainless steel in dilute sulfuric acid solution. Jmepeg. 2017; 26: 3450-3456.

[78] Olugbade, C. Liu, J. Lu. Enhanced passivation layer by Cr diffusion of 301 stainless steel facilitated by SMAT. Advanced Engineering Materials. 2019; 21: 125.

[79] Olugbade. Datasets on the corrosion behaviour of nanostructured AISI 316 stainless steel treated by SMAT. Data-inbrief. 2019; 25:104033.

[80] Olugbade, J. Lu. Enhanced corrosion properties of nanostructured 316 stainless steel in $0.6 \mathrm{M} \mathrm{NaCl}$ solution. J. Bio Tribo Corrosion. 2019; 5: 38.

[81] Olugbade, J. Lu. Characterization of the corrosion of nanostructured 17-4 PH stainless steel by surface mechanical attrition treatment (SMAT). Analytical Letters. 2019; 52: 2454-2471.

[82] B. AnushRaj, J. T. Winowlin Jappes, M. Adam Khan, et al. Studies on heat treatment and electrochemical behaviour 
of 3D printed DMLS processed nickelbased superalloy. Applied Physics A. 2019; 125: 722.

[83] D. Apparao, M. V. Jagannadha Raju. Experimental investigation on maraging steel metal deposition using DMLS process. International Conference on Emerging Trends in Engineering. 2020; 2: 721-730.

[84] Katarina Monkova, Ivana Zetkova, Ludmila Kucerova, et al. Study of 3D printing direction and effects of heat treatment on mechanical properties of MS1 maragingsteel. Archive of Applied Mechanics. 2019; 89: 791-804.

[85] C. A. Jagadish, Nadig Priyanka. Effect of cryogenic treatment on the mechanical properties of $18 \mathrm{Ni}-300$ grade maraging steel built using the direct metal laser sintering (DMLS) technology. Key Engineering Materials. 2017; 719: $114-121$.

[86] Hadadzadeh A., Amirkhiz B.S., Li J., et al. Microstructure evolution in direct metal laser sintered corrax maraging stainless steel. In: The minerals, metals \& materials series (eds) TMS 2019 148th annual meeting \& exhibition supplemental proceedings. The Minerals, Metals \& Materials Series. 2019; 455-462.

[87] Eva Schmidova, Premys Hojka, Bohumil Culek, et al. Dynamic strength and anisotropy of DMLS manufactured maraging steel. Communications Scientific Letters of the University of Zilina. 2019; 21(3): 35-39.

[88] Mooney, B., Kourousis, K. I., Raghavendra, R., et al. Process phenomena influencing the tensile and anisotropic characteristics of additively manufactured maraging steel. Materials Science and Engineering A. 2019; 745: 115-125.

[89] Yen-Ling Kuo, Shota Horikawa, Koji Kakehi. Effects of build direction and heat treatment on creep properties of Nibase superalloy built up by additive manufacturing. Scripta Materialia. 2017; 129: 74-78.

[90] Paul F. Kelley, Anil Saigal. Tensile and fatigue behavior of direct metal laser sintered (DMLS) INCONEL 718. Proceedings of the ASME 2015 International Mechanical Engineering Congress and Exposition. 2015; 13-19.

[91] O. Scott-emuakpor, J. Schwartz, T. George, et al. Bending fatigue life characterization of direct metal laser sintering nickel alloy 718. Fatigue Fract Engng. Mater Struct. 2015; 38: 1105-1117.

[92] C. D. Naiju, M. Adithan, P. Radhakrishnan, et al. Functional testing of direct metal laser sintered (DMLS) components for automotive application. Advanced Materials Research. 2012; 383: 6242-6246.

[93] Ezgi Uur Solakolu, Selim Gürgen, Melih Cemal Kuşhan. Surface topography of nickel-based superalloy manufactured with direct metal laser sintering (DMLS) method. Surface Topography, Metrology and Properties. 2019; 7: 1-23.

[94] K. L. Tan, S. H. Yeo. Surface modification of additive manufactured components by ultrasonic cavitation abrasive finishing. Wear. 2017; 378: 90-95.

[95] Sateesh N. H, Mohan kumar.G. C, Parsadkrishna, et al. Microstructure and mechanical characterization of laser sintered inconel-625 superalloy. Procedia Materials Science. 2014; 5: 772-779.

[96] Sankaranarayanan seetharaman, manickavasagam krishnan. Research updates on the additive manufacturing of nickel based superalloy. Solid Freeform Fabrication 2016, Proceedings of the 27th Annual International Solid Freeform Fabrication Symposium-An Additive Manufacturing Conference Reviewed Paper. 2016: 469-486.

[97] Scott-Emuakpor, Onome, George, et al. Material property determination of vibration fatigued DMLS and cold-rolled nickel alloys. Proceedings of the ASME turbo exp; düsseldorf, germany. Structures and Dynamics. 2014: 7A.

[98] Hastelloy X. Haynes international. 2015. Available from: http://www.haynesintl.com/alloys/alloy-portfolio_/Hightemperature-Alloys/Hastelloy-X-alloy.aspx.

[99] Romero-Jabalquinto A, Velasco-Tellez A, Zambrano-Robledo P. Feasibility of manufacturing combustion chambers for aeronautical use in Mexico. Journal of Applied Research and Technology. 2016; 14(3): 167-172.

[100]Bhadeshia, H. K. D. H. Nickel based superalloys. University of cambridge. Available from: http://www.msm.cam. ac.uk/phase-trans/2003/Superalloys/superalloys.html.

[101] Ascione, Adam. What is the difference between hastelloy and incoloy, continental steel \& tube company. 2015. Available from: http://www.metalspecialist.continentalsteel.com/blog/what-is-the-difference-between-hastelloy-andincoloy.

[102]Reza Abbaschian, Lara Abbaschian, Robert E. Reed hill, physical metallurgy principles. 4th ed., Stanford, CT, Cengage Learning. 2009.

[103]Tnickchi, A Alfantazi. Electrochemical corrosion behaviour of incoloy 800 in sulphate solutions containing hydrogen peroxide. Corrosion Science. 2010; 52(12): 4035-4045.

[104]Cabrini M, Lorenzi S, Testa C, et al. Microstructure and selective corrosion of alloy 625 obtained by means of laser powder bed fusion. Materials. 2019; 12(11): 1742.

[105]B. Anush Raj, J. T. Winowlin Jappes, M. Adam Khan, et al. Studies on heat treatment and electrochemical behaviour of 3D printed DMLS processed nickel-based superalloy. Applied Physics A. 2019; 125: 722.

[106]X. W. Baldwin. Metallography and microstructures handbook. ASM Int. 2004; 9: 2733.

[107]Beuer F, Schweiger J, Edelhoff D. Digital dentistry, an overview of recent developments for CAD/CAM generated restorations. Br Dent J. 2008; 204: 505-11.

[108]Alharbi N, Wismeijer D, Osman RB. Additive manufacturing techniques in prosthodontics, where do we currently stand? A critical review. Int J Prosthodont. 2017; 30: 474-84. 
[109]Arnold C, Hey J, Schweyen R, et al. Accuracy of CAD-CAM-fabricated removable partial dentures. J Prosthet Dent. 2018; 119: 586-592.

[110]Simel Ayyıldız, Elif Hilal Soylu, Semra İde, et al. Annealing of Co-Cr dental alloy, effects on nanostructure and Rockwell hardness. J Adv. Prosthodont. 2013; 5: 471-478,

[111]G. Barucca, E. Santecchia, G. Majni, et al. Structural characterization of biomedical Co-Cr-Mo components produced by direct metal laser sintering. Materials Science and Engineering C. 2015; 48: 263-269.

[112]Bawane, K. K., Srinivasan, D., Banerjee, D. Microstructural evolution and mechanical properties of direct metal laser-sintered (DMLS) Co Cr Mo after heat treatment. Metal and Mat Trans A. 2018; 49(9): 3793-3811.

[113]Lewis, G. Properties of open-cell porous metals and alloys for orthopaedic applications. Journal of Materials Science Materials in Medicine. 2013; 24(10): 2293-2325.

[114]Theodoros Koutsoukis, Spiros Zinelis, George Eliades, et al. Selective laser melting technique of Co-Cr dental alloys, a review of structure and properties and comparative analysis with other available techniques. Journal of Prosthodontic. 2015; 24(4): 303-312.

[115]Tatjana Puskar, Danimir Jevremovic, Robert J. Williams, et al. A comparative analysis of the corrosive effect of artificial saliva of variable pH on DMLS and cast Co-Cr-Mo dental alloy. Materials. 2014; 7: 6486-6501.

[116]Diana-Irinel Balia, Oana-Catalina Mocioiu, Catalin Zaharia, et al. Bioactivity of Co-Cr alloy samples sintered by DMLS process and coated with hydroxyapatite obtained by sol-gel method. Academia Romana. 2015; 60(9): 921930.

[117]Diana-Irinel Baila. Dental restorations of Co-Cr using direct metal laser sintering process. International Journal of Materials Mechanics and Manufacturing. 2018; 6(2): 94-98.

[118]E. Girardin, G. Barucca, P. Mengucci, et al. Biomedical Co-Cr-Mo components produced by direct metal laser sintering. Materials Today Proceedings. 2016; 3: 889-897.

[119]Yoshimitsu Okazak, Akira Ishino, Shizuo Higuchi. Chemical, physical, and mechanical properties and microstructures of laser-sintered Co-25Cr-5Mo-5W(SP2) and W-Free Co-28Cr-6Mo alloys for dental applications. Materials. 2019; 12: 4039.

[120]J. Schweiger, Jan-FrederikGüth, Kurt-Jürgen Erdelt, et al. Internal porosities, retentive force, and survival of cobaltchromium alloy clasps fabricated by selective laser-sintering. G Model, JPOR. 2019; 589: 1-7.

[121]Yager S, Ma J, Ozcan H, et al. Mechanical properties and microstructure of removable partial denture clasps manufactured using selective laser melting. AdditManuf. 2015; 8: 117-123.

[122]Joguet D, Costil S, Liao H, et al. Porosity content control of CoCrMo and titanium parts by taguchi method applied to selective laser melting process parameter. Rapid Prototyp J. 2016; 22: 20-30.

[123]Yurdanur Ucar, Orhun Ekren. Effect of layered manufacturing techniques, alloy powders and layer thickness on mechanical properties of Co-Cr dental alloys. The journal of prosthetic dentistry. 2018; 120: 762-770.

[124]Swee Leong Sing, Sheng Huang, Wai Yee Yeong. Effect of solution heat treatment on microstructure and mechanical properties of laser powder bed fusion produced cobalt-28chromium-6molybdenum. Materials Science \& Engineering A. 2020; 769: 138511.

[125]L. H. M. Antunes, J. J. Hoyos, E. B. Fonseca, et al. Effect of phase transformation on ductility of additively manufactured Co-28Cr-6Mo alloy, An in situ synchrotron X-ray diffraction study during mechanical testing. Materials Science \& Engineering A. 2019; 764: 138262.

[126]M. Béreš, C. C. Silva, P. W. C. Sarvezuk, et al. Mechanical and phase transformation behaviour of biomedical Co-CrMo alloy fabricated by direct metal laser sintering. Materials Science \& Engineering A. 2018; 714: 36-42.

[127]Liverani E, Fortunato A, Leardini A, et al. Fabrication of Co-Cr-Mo endoprosthetic ankle devices by means of selective laser melting (SLM). Materials \& Design. 2016; 106: 60-68.

[128]Bettini E, Eriksson T, Boström M, et al. Influence of metal carbides on dissolution behavior of biomedical CoCrMo alloy: SEM, TEM and AFM studies. Electro Acta. 2011; 56: 9413-9419.

[129]A. Takaichi, Suyalatu, T. Nakamoto, et al. Microstructures and mechanical properties of Co-29Cr-6Mo alloy fabricated by selective laser meltingprocess for dental applications. J. Mech. Behav. Biomed. Mater. 2013; 21: 67-76.

[130]Erica Liverani, Andrea Balbo, Cecilia Monticelli, et al. Corrosion resistance and mechanical characterization of ankle prostheses fabricated by selective laser melting. $3^{\text {rd }}$ CIRP conference on BioManufacturing, Procedia CIRP. 2017; 65: 25-31.

[131]S. Hiromoto, E. Onodera, A. Chiba, et al. Microstructure and corrosion behaviour in biological environments of the new forged low-Ni Co-Cr-Mo alloys. Biomaterials. 2005; 26: 4912-4923.

[132]Liyan Ma, Jia Niu. A comparison of corrosion behaviors of additive manufacturing cobalt-chromium alloy in different solutions. Metall. Res. Technol. 2019; 116: 311.

[133]Xian-zhen Xin, Jie Chen, Nan Xiang, et al. Surface properties and corrosion behavior of Co-Cr alloy fabricated with selective laser melting technique. Cell Biochem Biophys. 2013; 13: 9593-9599. 